\title{
The Perception in Saudi Learners of the English Bilabial Stops and the English Labio-Dental Fricatives
}

\author{
Salih Alzahrani ${ }^{1}$ \\ ${ }^{1}$ Department of Foreign Languages, Faculty of Arts, Taif University, Saudi Arabia \\ Correspondence: Salih Alzahrani, Department of Foreign Languages, Faculty of Arts, Taif University, Saudi \\ Arabia. E-mail: salihjam@hotmail.com
}

Received: October 22, 2020

Accepted: November 29, 2020

Online Published: January 22, 2021

doi:10.5539/ijel.v11n1p278

URL: https://doi.org/10.5539/ijel.v11n1p278

\begin{abstract}
Learning to produce and to identify sounds (phonemes) is not the same as learning the difference between sounds which leads to meaning delivery. One part of the acquisition of phonetics is the ability to perceive sounds which distinguish differences in meaning. This paper explores the perception in Saudi learners of the English Bilabial Stops /p/ and /b/ and the English Labio-dental Fricatives /f/ and /v/. Four different groups took part in this experiment. These groups were divided according to their age and their exposure to English either in English speaking countries or elsewhere. The participants had to listen to the different phonemes occurring initially, medially and finally. One of these groups of words contained non-sense words to test the participants' mis-perceptions when they do not recognize the sounds as part of their mental lexical knowledge. The results show these four groups faced difficulties perceiving and recognizing some sounds according to their exposure to English. Two groups, consisting of adults and children, showed very few misperceptions and/or missed sounds because they studied English in Australia for more than three years. Children had better perception than adults. The other groups show to had more misperceptions and/or missed sounds. Participants who had studied English in Australia for less than six months showed fewer misperceptions than those participants who had studied English in Saudi Arabia. This study suggests that teaching articulation (pronunciation) to Saudi learners of English in early stages is essential in order to avoid unconscious miscommunications due to the wrong perception and production of phonemes.
\end{abstract}

Keywords: phonetics, English phonemes, bilabial stops, labio-dental fricatives, Saudi learners, perception

\section{Introduction}

No one can ignore that languages, at least, human spoken languages, share some phonemes, but they also differ with regard to phonemes. That is, a phoneme (a basic sound element that distinguishes one sound from another) which can be found in English, for instance, is not necessarily to be found in other languages such as Arabic. English has some sounds which do not exist in Arabic such as /p/ and /v/. Similarly, Arabic has sounds which do not exist in English like the pharyngeal fricative $/ \hbar /$. Therefore, Arabic speakers who speak English as a second language find it difficult to distinguish aurally and orally between $/ \mathrm{p} / \mathrm{vs} / \mathrm{b} /$ and $/ \mathrm{v} / \mathrm{vs} / \mathrm{f} /$. This essay focuses on Saudi students as a second language learners of English (ESL/EFL) as participants who will undergo the experiment of the perception of the distinct Bilabial Stops phonemes $/ \mathrm{p} / \mathrm{vs} / \mathrm{b} /$ and Labiodental Fricatives phonemes $/ \mathrm{v} / \mathrm{vs} / \mathrm{f} /$. As a result of this experiment, we will answer the question "Do Saudi Arabian second language learners misperceive the /p/ and / $/$ / sounds of English?" I hypothesize that they will find it difficult to recognize these sounds and even sometimes find it impossible to hear them depending on their exposure to the language and their age when they start learning English.

\section{Background and Literature Review}

Learning a foreign language (as a second language (L2)) in a particular environment and exposure impacts on the learning processes. This learning process starts with the acquisition of L2 sounds. Many factors might contribute to this either positively or negatively according to the similarities and the differences between L1 and L2 with regard to many aspects including the phonetics. Age is also crucial when it is linked to learning a new language. That is, early bilinguals have the possibility to have complete "control" of a second language phonetic system (Lenneberg, 1967; Penfield, 1953; Penfield \& Roberts, 1959; Seliger, 1978). Beardsmore (1986) claims that these learners might be monolingual. 
Therefore, studies which focus on investigating the acquisition of English phonemes, as a second language can contribute significantly to the field of linguistics involving teaching and learning English as a second language. Saying that, it is important to mention that studies vary according to their goals. One area of interest is that which tries to investigate and to compare the speech perception and production of different phonemes on those sounds which are challenging for second language learners. Saudi learners (ESL/EFL) find it difficult to perceive and/or produce phonemes such as the English Bilabial stops /b/ and /p/ and the English Fricatives / $/$ and $/ \mathrm{v} /$. It is assumed that a language, that has the most marked /b/, should have the least marked sound $/ \mathrm{p} /$ (Prince \& Smolensky, 1993). However, this is not the case in Arabic because Arabic has /b/ but not /p/. Hence, this study is important.

\subsection{Previous Studies}

There are very few studies, which address the perception and the production of English sounds including both consonants and vowels. Some of these studies were conducted on speakers of Arabic and some others include speakers of other languages. Mack (1989) is one important study where the focus was on consonants and vowels perception and production by early English-French bilingual and English monolingual speakers. This study includes many experiments and concludes that the phonetic systems of early adult bilinguals are approximate but not as the same as those of monolinguals. In contrast, the early English-French bilinguals performed the same as the monolinguals. Moskowits (1975) conducted a study on early stages of child acquisition of fricatives. Moskowits suggests that the learning child acquires the phonetic and the phonological information in different ways. However, it is claimed that phonological acquisition is by far more regular than the phonetic one. Other studies include other learners from different backgrounds. Hattori and Iverson (2009); Kusumoto (2012) suggest that Japanese learners of English as a second and/or foreign language (ESL/EFL) are shown to have difficulties distinguishing between /1/ and /r/ after many years of English education. Zhang (2009) found that English learners in China are shown to have problems producing sounds which do not exist in their native language. Mohammad Hossein (2017) conducted a similar study on HAUSA speaking learners of English where they also experience some difficulties. Cheon (2005) investigated a similar study focusing on the perception and the production of English fricatives on Korean learners. Similar results also occurred to show that Korean learners of English face problems acquiring English sounds. Youfu and Yalun (2002) studied the pronunciation problems Thai learners of English (ESL/EFL) have which include both English consonants and vowels. Leelawadee (2011) and Sasiwimon (2013) conducted a study on Thai students at Wall Street Institute where the focus was on the production of some English phonemes where they found the students replace $/ 1 /$ with $/ \mathrm{r} /$ in word-initial position. Phosrithong (2017) conducted a comprehensive study where she studied the perception of English initial consonants sounds concluding with similar results where learners of English as a second language have difficulties and face problems producing the English sounds.

In addition, there are also several studies which focus on learners of English (ESL/EFL) from Arabic background as their native language. Moustafa (1979) investigated a group of Egyptian Arabic speakers. The results show that they have a perceptual difficulty with the bilabial phoneme $/ \mathrm{p} /$. They perceived /p/ sound almost the same as /b/ (Moustafa, 1979, p. 440). Khattab (2000) studied children's production of voiced and voiceless stops of monolingual and bilingual Lebanese Arabic and English-speaking children. He suggests that age plays an important role with regard to language acquisition. Elkhair (2014) conducted a study in pronunciation problem on Sudanese learners of English at Sudan University. The study shows that the learners face problems in pronunciation with some English consonants such as $/ \mathrm{z} /$ and $/ \mathrm{\delta} /, \mathrm{s} / \mathrm{s}$ and $/ \Theta /, / \mathrm{b} / \mathrm{and} / \mathrm{p} /, / \mathrm{g} /$ and $/ \mathrm{t} /$.

Some other studies focus on Saudi Gulf Arabic. Flege's (1980) and Flege and Port's (1981) studies investigated Saudi where three experiments revealed the issues that these learners have with relation to the perception and production of English stops. A similar study by Rasmussen (2007) having Arabic listeners (all from the Gulf region: Qatar, Saudi Arabia, and the United Arab). The study also proves that Arabic learners might have some difficulties when they are compared with American English listeners. Buali (2010) conducted a similar study where the focus was on the perception and production of the English bilabial /p/ in Saudi Gulf Arabic English. Alshangiti (2015) conducted a study to investigate speech production and perception in adult Arabic learners of English (ESL/EFL). This study focuses on a comparative study of the role of production and perception training in the acquisition of British English vowels.

\section{Methodology}

The aim of this study was to test the perception of the English Bilabial Stops $/ \mathrm{p} /$ and $/ \mathrm{b} /$ and the English Labiodental Fricatives /f/ and /v/. The participants, involved in this study, were some students from Saudi Arabia as second language speakers. The test was accomplished by using some minimal pairs for each phoneme 
occurring in different environments (word initial position, word medial position and word final position). Some non-sense words were used to ensure accurate findings. Each section involved repetition of some words in order to check the participants' choices. I chose five minimal pairs for each phoneme in three different environments. These minimal pairs were produced randomly by a native speaker of English. The participants had only the phonemes written in front of them for each minimal pair. All they had to do was to tick the sound that they heard. If they were unable to decide, they could skip the sound and move to the next one. There was no repetition for these words in order to get better results. After analysing the results, we were able to see to what extent these Arab speakers could distinguish between these four phonemes.

\section{Arabic and English Consonants}

There are eighteen common consonants (phonemes) between Arabic and English as shown in Table 1 below. These phonemes are not always identical although they exist in both languages. For example, $/ \mathrm{h} / \mathrm{has}$ a different distribution where Arabic can have this sound appear freely in initially, medially and finally. However, this sound occurs either initially or medially in English but not in the final positions. On the other hand, some English and Arabic phonemes do not share the same place of articulation. For example, the alveolar $/ t /$ is a dental sound in Arabic.

Table 1. Common consonants between English and Arabic

\begin{tabular}{|c|c|c|c|}
\hline & Common phonemes & English example & Arabic example \\
\hline 1. & $/ \mathrm{b} /$ & base & badr: "moon" \\
\hline 2. & $/ \mathrm{t} /$ & tea & tamr: "dates" \\
\hline 3. & $/ \mathrm{d} /$ & drink & dahr: "period" \\
\hline 4. & $/ \mathrm{k} /$ & key & karam: "generosity \\
\hline 5. & /3/ & jail & 3ara: "run" \\
\hline 6. & $/ f /$ & for & fam: "mouth" \\
\hline 7. & $/ \theta /$ & thought & $u$ ugb: "hole" \\
\hline 8. & /ठ/ & there & ð२: “wolf” \\
\hline 9. & $/ \mathrm{s} /$ & see & saqf: "roof" \\
\hline 10. & $|z|$ & zoo & za:r: "visited" \\
\hline 11. & $/ \mathrm{d} /$ & shoe & famal: "north" \\
\hline 12. & $/ \mathrm{h} /$ & hero & hawa?: "air" \\
\hline 13. & $/ 1 /$ & lion & lann: "won't" \\
\hline 14. & $/ \mathrm{m} /$ & milk & mahr: "dowery" \\
\hline 15. & $/ \mathrm{n} /$ & no & $n m r$ : "tiger" \\
\hline 16. & $/ \mathrm{w} /$ & week & wald: "boy" \\
\hline 17. & $/ \mathrm{r} /$ & rate & raqm: "number" \\
\hline 18. & $/ \mathrm{j} /$ & yes & Jad: "hand" \\
\hline
\end{tabular}

However, some phonemes occur in English including /p/, /g/, / $\check{C} /, / \mathrm{d} /$ and $/ \mathrm{y} /$ which do not exist in Arabic with the exception of $/ \mathrm{p} /$ and $/ \mathrm{g} /$. With regard to $/ \mathrm{p} /$, it can be heard in Arabic as an allophone in certain environments such as in libs: "dress". /b/ is devoiced in Arabic when a voiceless phoneme follows it (Alkhuli, 2007). However, it occurs as an allophone [p]. That is, unlike English, it is a phonetic difference which leads to no impact on the outcome of the meanings. Thus, $/ \mathrm{p} /$ is phonemic in English where it affects the meanings as in pad and bad. In addition, /g/ is usually heard in most Arabic dialects such as Saudi dialects but it does not exist in Modern Standard Arabic.

Arabic, on the other hand, also has its own specific phonemes which do not exist in English including $/ \mathrm{d}^{\mathrm{s} /} / \mathrm{d}^{\mathrm{s}} /$, $/ \mathrm{t}^{\mathrm{f}} /, / \mathrm{s}^{\mathrm{q}} /, / \mathrm{q} /, \mid \chi /, / \mathrm{s} /, / \mathrm{h} /, / \mathrm{q} /, / \mathrm{P} /$. These phonemes, which are Arabic restricted phonemes, do not exist in English not even as an allomorph.

\section{Arabic and English Bilabial Stops}

A stop (plosive or occlusive) is a consonant sound (phoneme), which is produced by stopping the airflow in the vocal tract. In particular, $/ \mathrm{p} /$ and $/ \mathrm{b} /$ are bilabial stops, with the airstream stopped at the mouth by the complete closure of the lips. The terms plosive and stop are usually used interchangeably, but they are not perfect synonyms. Plosives are stops with a pulmonic egressive airstream mechanism. All languages in the world have stops and most have at least /p/,/t/, /k/, /n/ and /m/ (Maddieson, 1984). 


\subsection{Bilabial Stop Articulation}

Place of articulation: When we produce a $/ \mathrm{p} /$ or $/ \mathrm{b} /$ as in $\mathrm{pad}$ and $\mathrm{bad}$, we articulate by bringing both lips together. Therefore, they are called bilabials.

In the articulation of the stop, three processes can be observed and distinguished (Giegerich, 1992; Jensen, 1993; McMahon, 2002; Roca, 2004; Fromkin, 2014):

- Catch: The airway stops during which air cannot go through the oral cavity and that is why it is called stop. With regard to the nasal stops, the air escapes through the nose.

- Hold or occlusion: The airway stays closed, causing a pressure difference to build up and that is why it is called occlusive.

- Release or burst: The closure is opened allowing airflow to pass through. With regard to the plosives, the released airflow produces a sudden impulse causing an audible sound and therefore it is called plosive.

Arabic has only one bilabial stop [b] as a (voiced) phoneme (Naqshabandi, 1988) Watson (2007) whereas English has two bilabial stops [p] (voiceless) and [b] (voiced), (Fromkin, 2014; Yule, 2020).

\subsection{Similarities and Differences}

The Arabic /b/ is similar to the English /b/ as in back. This sound, as mentioned before, is produced by complete closure of the lips, stopping the airflow in the mouth and then releasing it. It can occur initially, medially and finally (e.g., $b \bar{a} b$ : "door", $m a t^{\varsigma} b \chi$ : "kitchen" and $\hbar u b$ : "love"). This voiced bilabial stop is often devoiced next to voiceless sounds or if it occurs finally though the voicing contrast is not a distinctive feature (Alkhuli, 2007). That is, the meaning does not change if it is devoiced, as mentioned in Section 4 earlier. For example, Pasabt: "Saturday" and žăb: "bring". In the first example, the /b/ phoneme is followed by the voiceless stop /t/; in the other example, the /b/ sound occurs at the end of the word preceded by a long vowel. Therefore, in both cases the $/ \mathrm{b} /$ sound was devoiced. With regard to the initial position, the $/ \mathrm{b} /$ sound is never devoiced because consonant clusters do not occur at the beginning of words Watson (2007). Arabic speakers also use vowel epenthesis to make the English consonant sequence comply with their own syllabic structure. However, speakers differ in where they insert the vowel according to the syllabification rules of their own variety of Arabic. So, it is important to state that there is no \pm voice contrast with bilabial stop phoneme $/ \mathrm{b} /$.

On the other hand, the English $/ \mathrm{b} /$ is voiced and the $/ \mathrm{p} /$ phoneme is voiceless and both sounds can occur initially, medially and finally (e.g., back, play; mobile, apple; and mop, mob). Unlike Arabic, the phoneme $/ \mathrm{b} /$ has its voiceless counterpart $/ \mathrm{p} /$ where the voicing is the distinctive feature that distinguishes between the minimal pairs such as pay and bay. It shows to have an impact on the meaning. However, most English speakers do not voice the initial /b/ fully, and it becomes devoiced when it appears finally as in rip and rib (Roca, 2004). Native speakers can distinguish the $/ \mathrm{b} /$ from $/ \mathrm{p} /$ in this environment as the preceding vowel is lengthened before the originally voiced one. This makes it even harder for non-native speakers to perceive the intended sound.

\section{Arabic and English Labio-Dental Fricatives}

Labiodental Fricative sounds /f/ or $/ \mathrm{v} /$ are produced by touching the bottom lip to the upper teeth. Therefore, they are called labio-dentals. The airflow is so severely obstructed that it causes friction. The friction is created at the lips and teeth, where a narrow passage permits the air to escape (Roca, 2004; Fromkin, 2014). /f/ is a voiceless sound whereas $/ \mathrm{v} /$ is a voiced one. Arabic does not contain $/ \mathrm{v} /$.

"Unlike English, Arabic utilizes durational differences of both vowels and consonants to make phonemic distinction." (The vowel effect was found to be minimal and only among the non-sibilant fricatives and similar results were obtained by Pirello, Blumstein, and Kurowski (1997)). It is of interest, therefore, to see how such durational property would affect voicing and place classification of Arabic fricatives" (Alkhairy, 2005). Therefore, durational differences of both vowels and consonants for phonemic distinctions are available for all phonemes in any language. However, I claim that Arabic does not show to have any impact of durational differences of both vowels and consonants in the case of $/ f /$. That is, /f/ is not the same as $/ \mathrm{b} /$ which has $[\mathrm{p}]$ as an allophone in some Arabic examples, as discussed earlier.

\section{Case Study}

This section discusses the questionnaire, the findings and the analysis and discussion.

\subsection{The Questionnaire}

The questionnaire is divided basically into two sections. Both these two sections are divided into three other 
parts according to the environment where the sound can be heard (initially, medially and finally). As mentioned above, it is obvious that voicing differs according the environment of phonemes. For example, the final positions of the sound $/ \mathrm{p} /$ and $/ \mathrm{b} /$ where they are devoiced.

In each environment, there will be eleven words. Minimal pairs for each phoneme occurring in different environments (word initial position, word medial position and word final position) are used. Some non-sense words are used to ensure accurate findings. Each section will involve repetition of some words in order to check the participants' choices. More details are provided in the methodology section.

Forty subjects undertook the test. They were divided into four groups according to their exposure to English and their environment of the study. Also, participants were chosen from different levels in terms of their education. That is, the length of time they had studied English (will be indicated later). They were given five minutes to read the instructions and to see an example of what they were going to do. In addition to that, everything with regard to the experiment was explained including each section before the recordings were played.

Unfortunately, although all preparations and arrangements were done to conduct this project effectively, there were some obstacles such as the ability to find participants for the different groups I had chosen. Some equipment was needed to guarantee the quality of the recordings. For example, a recording laboratory was important by which all the participants did the experiment at the same time and in the same setting. Moreover, although there should have been some other sounds such as $/ \mathrm{t} /$ and $/ \mathrm{d} / \mathrm{or} / \Theta /$ and $/ \mathrm{d} /$ in order to compare them with the chosen phonemes. However, this experiment was considered sufficient to come up with reliable results.

\subsection{The Results}

This section shows the results according to their previous division and according to the numbers that are given to each participant to make their names anonymous.

7.2.1 Misperception of Initial /p/, /b/, /f/ and /v/

Table 2. Misperception of Initial /p/, /b/, /f/ and /v/- Group A

\begin{tabular}{llllll}
\hline Participant's group & Participant's number & Initial /p/ & Initial /b/ & Initial /f/ & Initial /v/ \\
\hline Group A & 1 & $0 / 6$ & $0 / 5$ & $0 / 5$ & $0 / 6$ \\
& 2 & $0 / 6$ & $1 / 5$ & $0 / 5$ & $1 / 6$ \\
& 3 & $0 / 6$ & $0 / 5$ & $0 / 5$ & $1 / 6$ \\
& 4 & $0 / 6$ & $0 / 5$ & $0 / 5$ & $0 / 6$ \\
& 5 & $0 / 6$ & $1 / 5$ & $0 / 5$ & $1 / 6$ \\
& 6 & $1 / 6$ & $1 / 5$ & $0 / 5$ & $2 / 6$ \\
& 7 & $1 / 6$ & $0 / 5$ & $0 / 5$ & $1 / 6$ \\
& 8 & $0 / 6$ & $0 / 5$ & $0 / 5$ & $0 / 6$ \\
& 9 & $0 / 6$ & $1 / 5$ & $0 / 5$ & $1 / 6$ \\
& 10 & $1 / 6$ & $0 / 5$ & $0 / 5$ & $1 / 6$ \\
\hline
\end{tabular}

Table 3. Misperception of Initial /p/, /b/, /f/ and /v/- Group B

\begin{tabular}{llllll}
\hline Participant's group & Participant's number & Initial /p/ & Initial /b/ & Initial /f/ & Initial /v/ \\
\hline Group B & 1 & $3 / 6$ & $2 / 5$ & $0 / 5$ & $3 / 6$ \\
& 2 & $2 / 6$ & $1 / 5$ & $2 / 5$ & $3 / 6$ \\
& 3 & $0 / 6$ & $2 / 5$ & $0 / 5$ & $3 / 6$ \\
& 4 & $0 / 6$ & $0 / 5$ & $0 / 5$ & $1 / 6$ \\
& 5 & $0 / 6$ & $0 / 5$ & $1 / 5$ & $1 / 6$ \\
& 6 & $1 / 6$ & $2 / 5$ & $0 / 5$ & $1 / 6$ \\
& 7 & $1 / 6$ & $2 / 5$ & $1 / 5$ & $2 / 6$ \\
& 8 & $3 / 6$ & $1 / 5$ & $1 / 5$ & $3 / 6$ \\
& 9 & $3 / 6$ & $3 / 5$ & $1 / 5$ & $3 / 6$ \\
& 10 & $4 / 6$ & $3 / 5$ & $2 / 5$ & $1 / 6$ \\
\hline
\end{tabular}

Table 4. Misperception of Initial /p/, /b/, /f/ and /v/- Group C

\begin{tabular}{llllll}
\hline Participant's group & Participant's number & Initial/p/ & Initial/b/ & Initial/f/ & Initial/v/ \\
\hline Group C & 1 & $0 / 6$ & $0 / 5$ & $0 / 5$ & $0 / 6$ \\
& 2 & $0 / 6$ & $0 / 5$ & $0 / 5$ & $0 / 6$ \\
& 3 & $0 / 6$ & $1 / 5$ & $0 / 5$ & $1 / 6$ \\
& 4 & $0 / 6$ & $1 / 5$ & $0 / 5$ & $1 / 6$ \\
& 5 & $0 / 6$ & $1 / 5$ & $1 / 5$ & $1 / 6$ \\
& 6 & $1 / 6$ & $1 / 5$ & $1 / 5$ & $1 / 6$ \\
\hline
\end{tabular}




\begin{tabular}{lllll}
\hline 7 & $1 / 6$ & $0 / 5$ & $0 / 5$ & $1 / 6$ \\
8 & $1 / 6$ & $0 / 5$ & $0 / 5$ & $1 / 6$ \\
9 & $0 / 6$ & $0 / 5$ & $0 / 5$ & $0 / 6$ \\
10 & $1 / 6$ & $1 / 5$ & $1 / 5$ & $1 / 6$ \\
\hline
\end{tabular}

Table 5. Misperception of Initial /p/, /b/, /f/ and /v/- Group D

\begin{tabular}{llllll}
\hline Participant's group & Participant's number & Initial /p/ & Initial /b/ & Initial /f/ & Initial /v/ \\
\hline Group D & 1 & $3 / 6$ & $1 / 5$ & $3 / 5$ & $5 / 6$ \\
& 2 & $3 / 6$ & $2 / 5$ & $1 / 5$ & $3 / 6$ \\
& 3 & $5 / 6$ & $4 / 5$ & $2 / 5$ & $3 / 6$ \\
& 4 & $4 / 6$ & $3 / 5$ & $2 / 5$ & $3 / 6$ \\
& 5 & $4 / 6$ & $3 / 5$ & $4 / 5$ & $5 / 6$ \\
& 6 & $5 / 6$ & $3 / 5$ & $3 / 5$ & $4 / 6$ \\
& 7 & $3 / 6$ & $1 / 5$ & $3 / 5$ & $4 / 6$ \\
& 8 & $4 / 6$ & $2 / 5$ & $2 / 5$ & $4 / 6$ \\
& 9 & $3 / 6$ & $2 / 5$ & $2 / 5$ & $3 / 6$ \\
& 10 & $4 / 6$ & $2 / 5$ & $2 / 5$ & $4 / 6$ \\
\hline
\end{tabular}

7.2.2 Misperception of Medial /p/,/b/, /f/ and / $/$

Table 6. Misperception of Medial /p/, /b/, /f/ and /v/ - Group A

\begin{tabular}{llllll}
\hline Participant's group & Participant's number & Medial /p/ & Medial /b/ & Medial /f/ & Medial /v/ \\
\hline Group A & 1 & $2 / 6$ & $1 / 5$ & $2 / 5$ & $1 / 6$ \\
& 2 & $3 / 6$ & $2 / 5$ & $3 / 5$ & $2 / 6$ \\
& 3 & $0 / 6$ & $0 / 5$ & $0 / 5$ & $0 / 6$ \\
& 4 & $2 / 6$ & $1 / 5$ & $0 / 5$ & $1 / 6$ \\
& 5 & $2 / 6$ & $0 / 5$ & $1 / 5$ & $1 / 6$ \\
& 6 & $1 / 6$ & $0 / 5$ & $0 / 5$ & $2 / 6$ \\
& 7 & $1 / 6$ & $0 / 5$ & $0 / 5$ & $0 / 6$ \\
& 8 & $2 / 6$ & $1 / 5$ & $1 / 5$ & $0 / 6$ \\
& 9 & $3 / 6$ & $2 / 5$ & $1 / 5$ & $2 / 6$ \\
& 10 & $3 / 6$ & $1 / 5$ & $2 / 5$ & $1 / 6$ \\
\hline
\end{tabular}

Table 7. Misperception of Medial /p/, /b/, /f/ and /v/ - Group B

\begin{tabular}{llllll}
\hline Participant's group & Participant's number & Medial /p/ & Medial /b/ & Medial /f/ & Medial /v/ \\
\hline Group B & 1 & $4 / 6$ & $3 / 5$ & $4 / 5$ & $1 / 6$ \\
& 2 & $0 / 6$ & $3 / 5$ & $3 / 5$ & $3 / 6$ \\
& 3 & $4 / 6$ & $1 / 5$ & $3 / 5$ & $2 / 6$ \\
& 4 & $1 / 6$ & $1 / 5$ & $2 / 5$ & $2 / 6$ \\
& 5 & $2 / 6$ & $1 / 5$ & $0 / 5$ & $2 / 6$ \\
& 6 & $2 / 6$ & $1 / 5$ & $3 / 5$ & $3 / 6$ \\
& 7 & $1 / 6$ & $2 / 5$ & $3 / 4$ & $4 / 6$ \\
& 8 & $1 / 6$ & $3 / 5$ & $2 / 5$ & $3 / 6$ \\
& 9 & $3 / 6$ & $3 / 5$ & $2 / 5$ & $2 / 6$ \\
& 10 & $3 / 6$ & $2 / 5$ & $3 / 5$ & $4 / 6$ \\
\hline
\end{tabular}

Table 8. Misperception of Medial /p/, /b/, /f/ and /v/ - Group C

\begin{tabular}{llllll}
\hline Participant's group & Participant's number & Medial /p/ & Medial /b/ & Medial /f/ & Medial /v/ \\
\hline Group C & 1 & $1 / 6$ & $2 / 5$ & $1 / 5$ & $1 / 6$ \\
& 2 & $0 / 6$ & $1 / 5$ & $1 / 5$ & $0 / 6$ \\
& 3 & $0 / 6$ & $0 / 5$ & $0 / 5$ & $0 / 6$ \\
& 4 & $1 / 6$ & $1 / 5$ & $1 / 5$ & $1 / 6$ \\
& 5 & $1 / 6$ & $2 / 5$ & $1 / 5$ & $2 / 6$ \\
& 6 & $0 / 6$ & $1 / 5$ & $1 / 5$ & $0 / 6$ \\
& 7 & $1 / 6$ & $1 / 5$ & $2 / 5$ & $1 / 6$ \\
& 8 & $0 / 6$ & $1 / 5$ & $1 / 5$ & $0 / 6$ \\
& 9 & $1 / 6$ & $1 / 5$ & $1 / 5$ & $1 / 6$ \\
& 10 & $0 / 6$ & $0 / 5$ & $0 / 5$ & $0 / 6$ \\
\hline
\end{tabular}


Table 9. Misperception of Medial /p/, /b/, /f/ and /v/ - Group D

\begin{tabular}{llllll}
\hline Participant's group & Participant's number & Medial /p/ & Medial /b/ & Medial /f/ & Medial /v/ \\
\hline Group D & 1 & $5 / 6$ & $2 / 5$ & $3 / 5$ & $4 / 6$ \\
& 2 & $4 / 6$ & $3 / 5$ & $3 / 5$ & $4 / 6$ \\
& 3 & $3 / 6$ & $3 / 5$ & $2 / 5$ & $3 / 6$ \\
& 4 & $3 / 6$ & $2 / 5$ & 15 & $3 / 6$ \\
& 5 & $3 / 6$ & $3 / 5$ & $3 / 5$ & $3 / 6$ \\
& 6 & $3 / 6$ & $5 / 5$ & $4 / 5$ & $4 / 6$ \\
& 7 & $2 / 6$ & $3 / 5$ & $2 / 5$ & $2 / 6$ \\
& 8 & $3 / 6$ & $3 / 5$ & $2 / 5$ & $3 / 6$ \\
& 9 & $2 / 6$ & $4 / 5$ & $2 / 5$ & $3 / 6$ \\
& 10 & $5 / 6$ & $5 / 5$ & $4 / 5$ & $5 / 6$ \\
\hline
\end{tabular}

7.2.3 Misperception of Final /p/, /b/, /f/ and /v/

Table 10. Misperception of Final /p/, /b/, /f/ and /v/ - Group A

\begin{tabular}{llllll}
\hline Participant's group & Participant's number & Final /p/ & Final /b/ & Final /f/ & Final /v/ \\
\hline Group A & 1 & $0 / 6$ & $3 / 5$ & $0 / 5$ & $1 / 6$ \\
& 2 & $2 / 6$ & $3 / 5$ & $0 / 5$ & $3 / 6$ \\
& 3 & $0 / 6$ & $0 / 5$ & $1 / 5$ & $1 / 6$ \\
& 4 & $1 / 6$ & $1 / 5$ & $0 / 5$ & $1 / 6$ \\
& 5 & $1 / 6$ & $1 / 5$ & $1 / 5$ & $1 / 6$ \\
& 6 & $1 / 6$ & $1 / 5$ & $0 / 5$ & $2 / 6$ \\
& 7 & $0 / 6$ & $0 / 5$ & $0 / 5$ & $0 / 6$ \\
& 8 & $0 / 6$ & $1 / 5$ & $1 / 5$ & $0 / 6$ \\
& 9 & $1 / 6$ & $2 / 5$ & $1 / 5$ & $2 / 6$ \\
& 10 & $1 / 6$ & $2 / 5$ & $2 / 5$ & $1 / 6$ \\
\hline
\end{tabular}

Table 11. Misperception of Final /p/, /b/, /f/ and /v/ - Group B

\begin{tabular}{llllll}
\hline Participant's group & Participant's number & Final $/ \mathbf{p} /$ & Final $/ \mathbf{b} /$ & Final $/ \mathbf{f} /$ & Final $/ \mathbf{v} /$ \\
\hline Group B & 1 & $3 / 6$ & $1 / 5$ & $3 / 5$ & $2 / 6$ \\
& 2 & $1 / 6$ & $2 / 5$ & $2 / 5$ & $4 / 6$ \\
& 3 & $2 / 6$ & $2 / 5$ & $2 / 5$ & $3 / 6$ \\
& 4 & $1 / 6$ & $1 / 5$ & $2 / 5$ & $2 / 6$ \\
& 5 & $2 / 6$ & $1 / 5$ & $0 / 5$ & $2 / 6$ \\
& 6 & $2 / 6$ & $2 / 5$ & $3 / 5$ & $3 / 6$ \\
& 7 & $2 / 6$ & $2 / 5$ & $3 / 5$ & $4 / 6$ \\
& 8 & $2 / 6$ & $1 / 5$ & $2 / 5$ & $3 / 6$ \\
& 9 & $2 / 6$ & $2 / 5$ & $2 / 5$ & $2 / 6$ \\
& 10 & $1 / 6$ & $2 / 5$ & $3 / 5$ & $4 / 6$ \\
\hline
\end{tabular}

Table 12. Misperception of Final /p/, /b/, /f/ and /v/ - Group C

\begin{tabular}{llllll}
\hline Participant's group & Participant's number & Final /p/ & Final /b/ & Final /f/ & Final /v/ \\
\hline Group C & 1 & $3 / 6$ & $0 / 5$ & $1 / 5$ & $1 / 6$ \\
& 2 & $0 / 6$ & $1 / 6$ & $1 / 5$ & $1 / 6$ \\
& 3 & $0 / 6$ & $0 / 5$ & $0 / 5$ & $0 / 6$ \\
& 4 & $1 / 6$ & $1 / 5$ & $1 / 5$ & $1 / 6$ \\
& 5 & $1 / 6$ & $1 / 5$ & $1 / 5$ & $2 / 6$ \\
& 6 & $1 / 6$ & $1 / 5$ & $0 / 5$ & $1 / 6$ \\
& 7 & $1 / 6$ & $1 / 5$ & $1 / 5$ & $2 / 6$ \\
& 8 & $0 / 6$ & $1 / 5$ & $0 / 5$ & $1 / 6$ \\
& 9 & $1 / 6$ & $1 / 5$ & $1 / 5$ & $1 / 6$ \\
& 10 & $0 / 6$ & $0 / 5$ & $0 / 5$ & $0 / 6$ \\
\hline
\end{tabular}


Table 13. Misperception of Final /p/, /b/, /f/ and /v/ - Group D

\begin{tabular}{llllll}
\hline Participant's group & Participant's number & Final /p/ & Final /b/ & Final /f/ & Final /v/ \\
\hline Group D & 1 & $4 / 6$ & $3 / 5$ & $4 / 5$ & $3 / 6$ \\
& 2 & $4 / 6$ & $3 / 5$ & $4 / 5$ & $3 / 6$ \\
& 3 & $3 / 6$ & $3 / 6$ & $3 / 5$ & $3 / 6$ \\
& 4 & $4 / 6$ & $1 / 5$ & $2 / 5$ & $3 / 6$ \\
& 5 & $4 / 6$ & $2 / 5$ & $3 / 5$ & $3 / 6$ \\
& 6 & $4 / 6$ & $4 / 5$ & $4 / 5$ & $4 / 6$ \\
& 7 & $3 / 6$ & $1 / 5$ & $3 / 5$ & $1 / 6$ \\
& 8 & $4 / 6$ & $1 / 5$ & $3 / 5$ & $2 / 6$ \\
& 9 & $3 / 6$ & $2 / 5$ & $3 / 5$ & $2 / 6$ \\
& 10 & $6 / 6$ & $3 / 5$ & $4 / 5$ & $5 / 6$ \\
\hline
\end{tabular}

\subsection{Analysis and Discussion}

From the previous sections, it is clear that there were four different groups, which were based on the participants' duration of the exposure to the language as well as the environment where they had the exposure. Doing this helped to differentiate between those participants who had their exposure to English in an English-speaking country from those who never been immersed in such an environment. The position of the sound determines its degree of the misperception, as will be discussed below. Although the misperception, that was identified, was not complete, there was evidence that there were misperceptions. These varied from one environment to another and from one participant to another. The following sections discuss the results in more detail.

Interestingly, Arabic and English, as mentioned earlier, share some of these sounds regardless of being voiced or not. Arabic has both the voiced phoneme /b/ and the voiceless one /f/. Therefore, voicing cannot be the reasoning for the misperception as shown in the following sections.

\subsubsection{The Initial / $/ \mathrm{p} /$ and $/ \mathrm{b} /$ Sounds}

By looking closely into the analysis of the data, it is evident that the subjects who had been in Australia for more than three years found it easier to perceive these initial sounds. The data show that there is a very slight chance of missing the sound(s) with six participants which is normal to happen with non-native speakers of English. Consider the following figure:

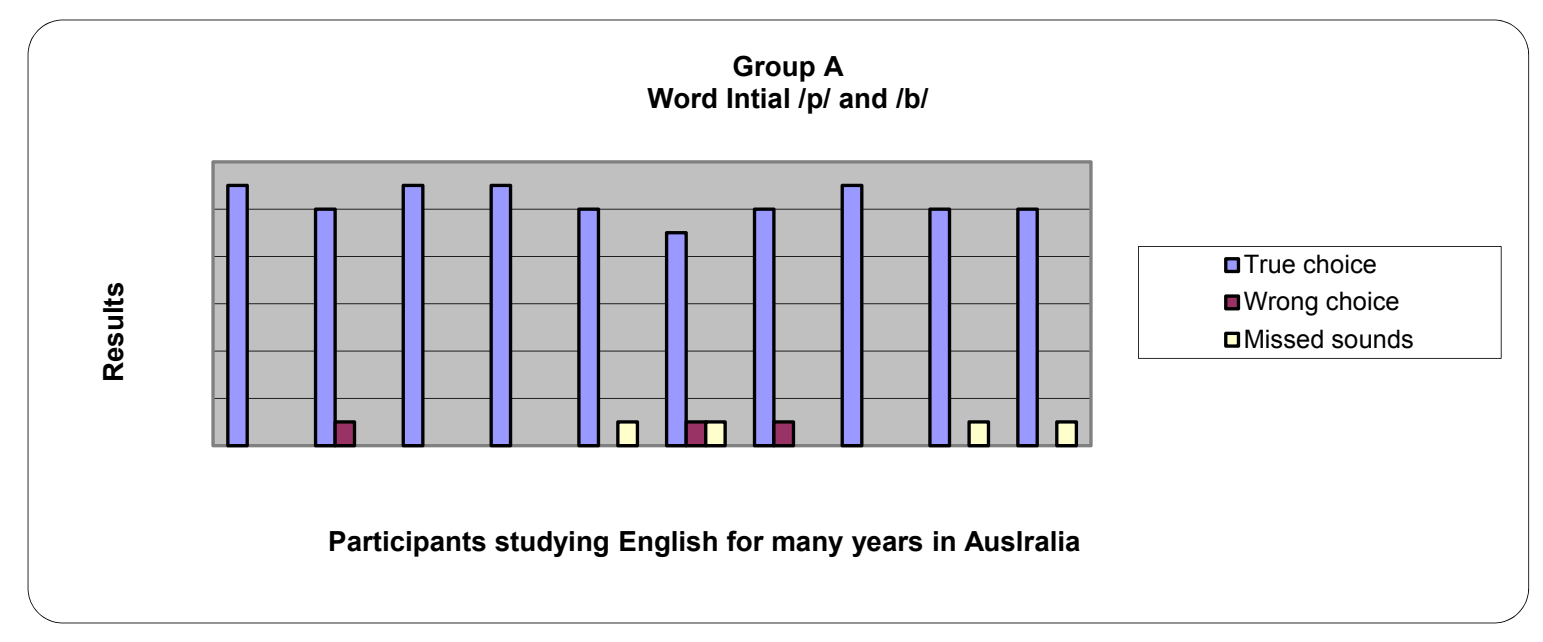

Figure 1. Participants studying English for many years in an English-speaking country

Group B, it represents those participants who had been studying English for less than six months at the time they did the experiment. The data show that the majority have misperception of the initial sounds. Only two of them were able to distinguish between $/ \mathrm{p} /$ and $/ \mathrm{b} /$ in the initial position. Three participants were not able to decide which sound they heard; one of them missed two words and the other two participants missed one word each of them as it is shown in Figure 2 below. 


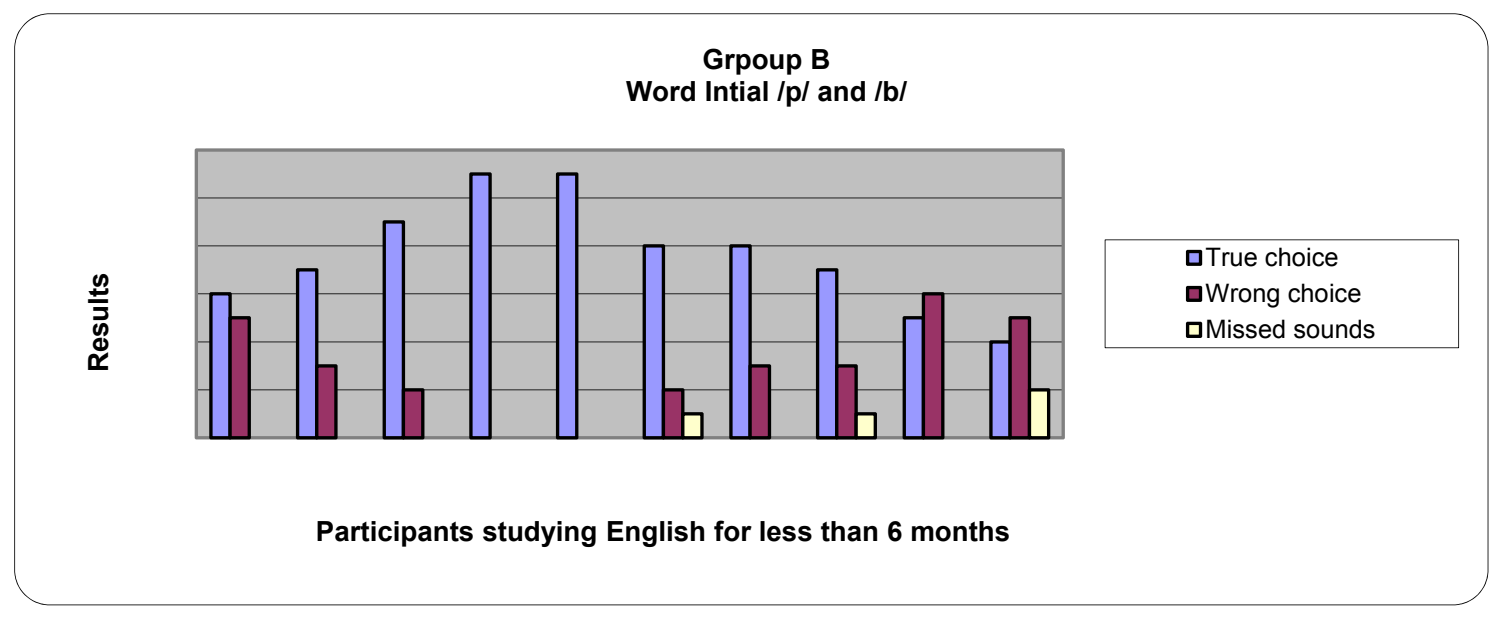

Figure 2. Participants studying English for less than six months in an English-speaking country

Group C is a different group as it consisted of some children who had had a greater exposure to English in earlier stages of their learning than other participants. This is an important factor if we take into consideration what Chomsky proposed regarding the critical period needed to acquire a language Chomsky (1965). Generally, participants in this group found no problems selecting the correct sounds they heard with some exceptions of four subjects who missed four words and/or sounds and five others who missed sounds where participants show they are not able to decide the correct phoneme, as shown in Figure 3 below.

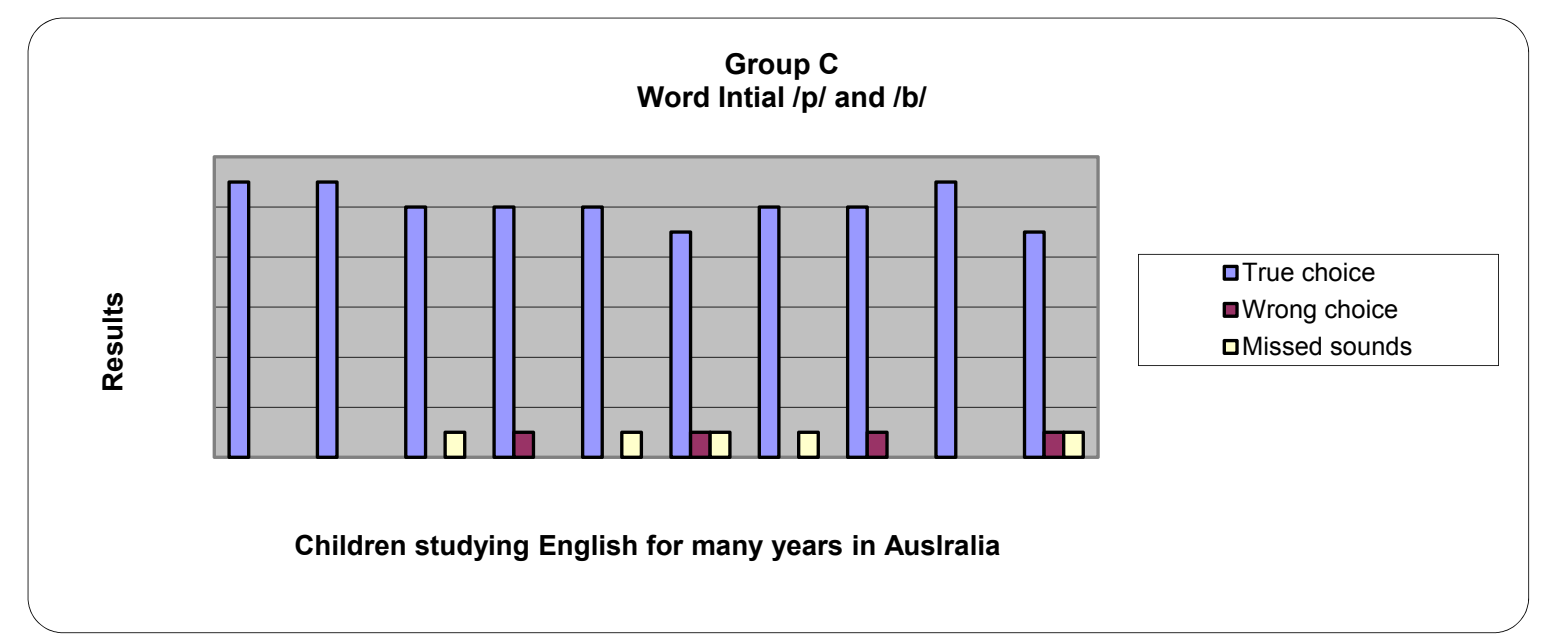

Figure 3. Children studying English for many years in an English-speaking country

Finally, Group D, which represents those participants who had been studying English for many years in Saudi Arabia. These participants had had no real exposure to English with native speakers of English. The data shows that although they had been studying English for many years, they had a considerable misperception of the initial sounds $/ \mathrm{p} /$ and $/ \mathrm{b} /$. It is seen through the data that the highest correct score was seven out of eleven and the highest misperception was eight as wrong answers. Also, this group show that they had difficulties in choosing some sounds. Consider the following figure: 


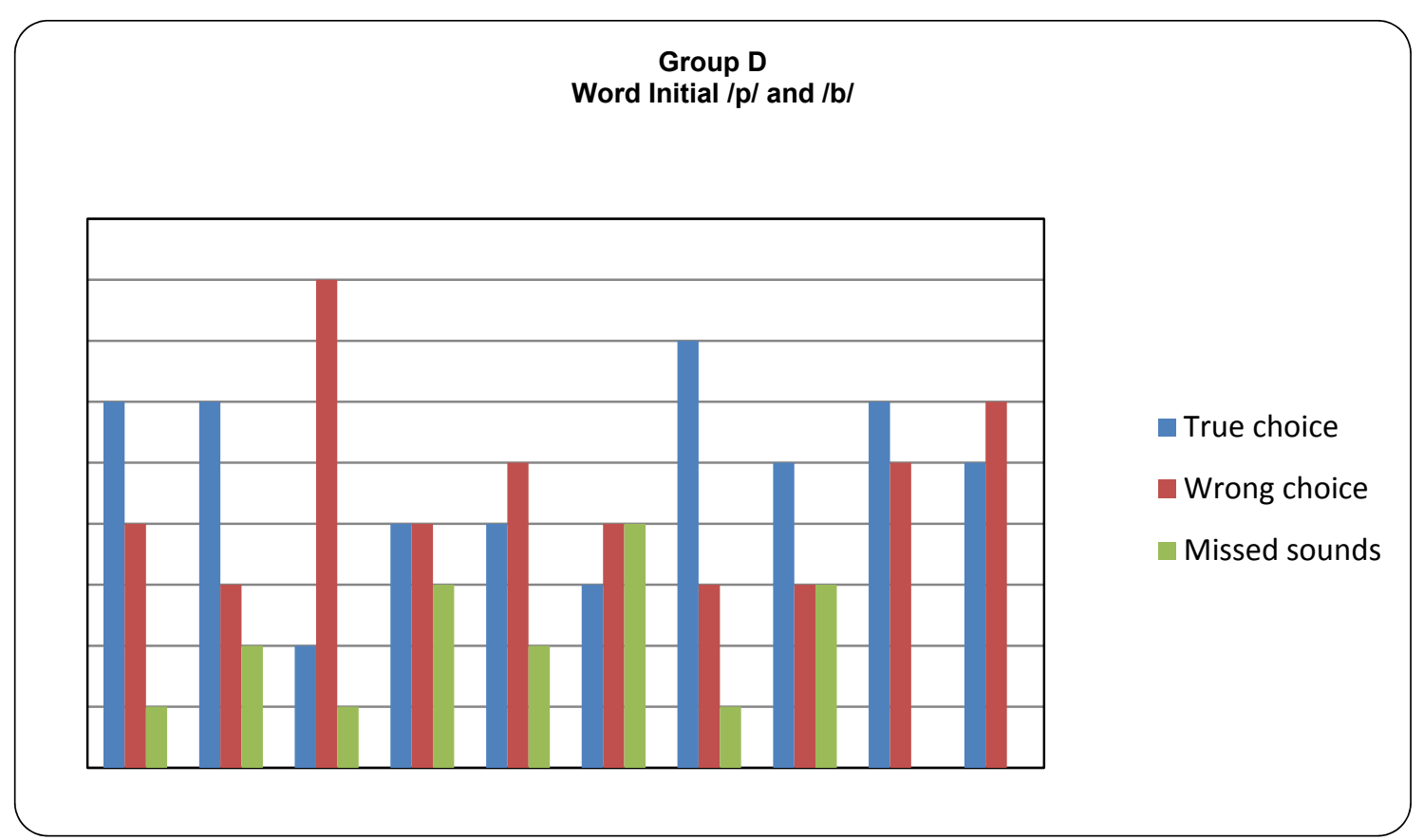

Figure 4. Participants studying English for many years in Saudi Arabia

\subsubsection{The Initial/f/ and /v/ Sounds}

Groups (A-D) did the same previous experiment but this time they had been tested to choose between /f/ and /v/ sounds. With regard to word initial position, Group A again showed that they had few misperceptions of the initial sounds $/ \mathrm{f} /$ and $/ \mathrm{v} /$. Three subjects made three wrong choices. Also, five participants showed that they were not able to decide the sounds they heard. This result was expectable because these participants did the experiment after spending many years in Australia. By saying this, I suggest that the close exposure to English within English speaking country is one clear reason why they had achieved high scores. Consider Figure 5 below:

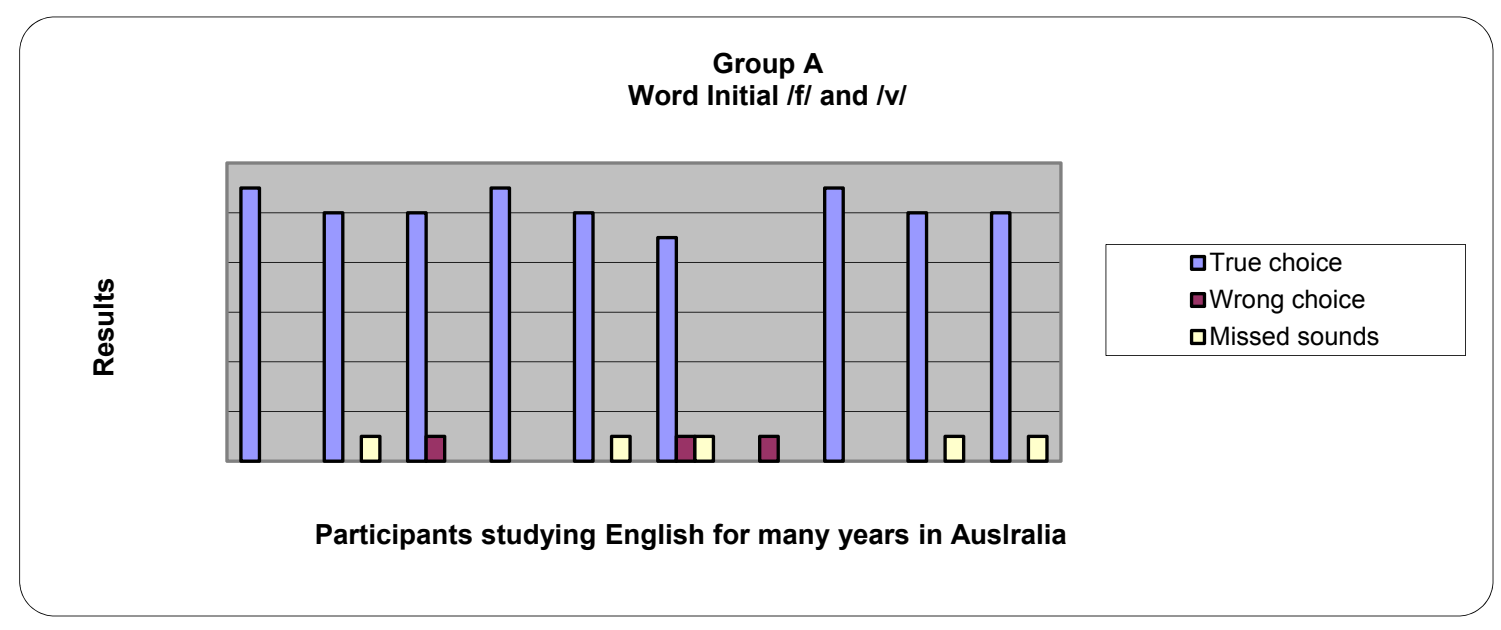

Figure 5. Participants studying English for many years in an English-speaking country

Group B who were experiencing similar environment to Group A did not show similar scores. It is basically clear that the period they spent in Australia is not sufficient to have a very high proficiency level. All the ten subjects made wrong choices with variation in the score from one participant to another. Participant 6 and participant 10 faced difficulties in choosing one of the correct sounds, as shown below. 


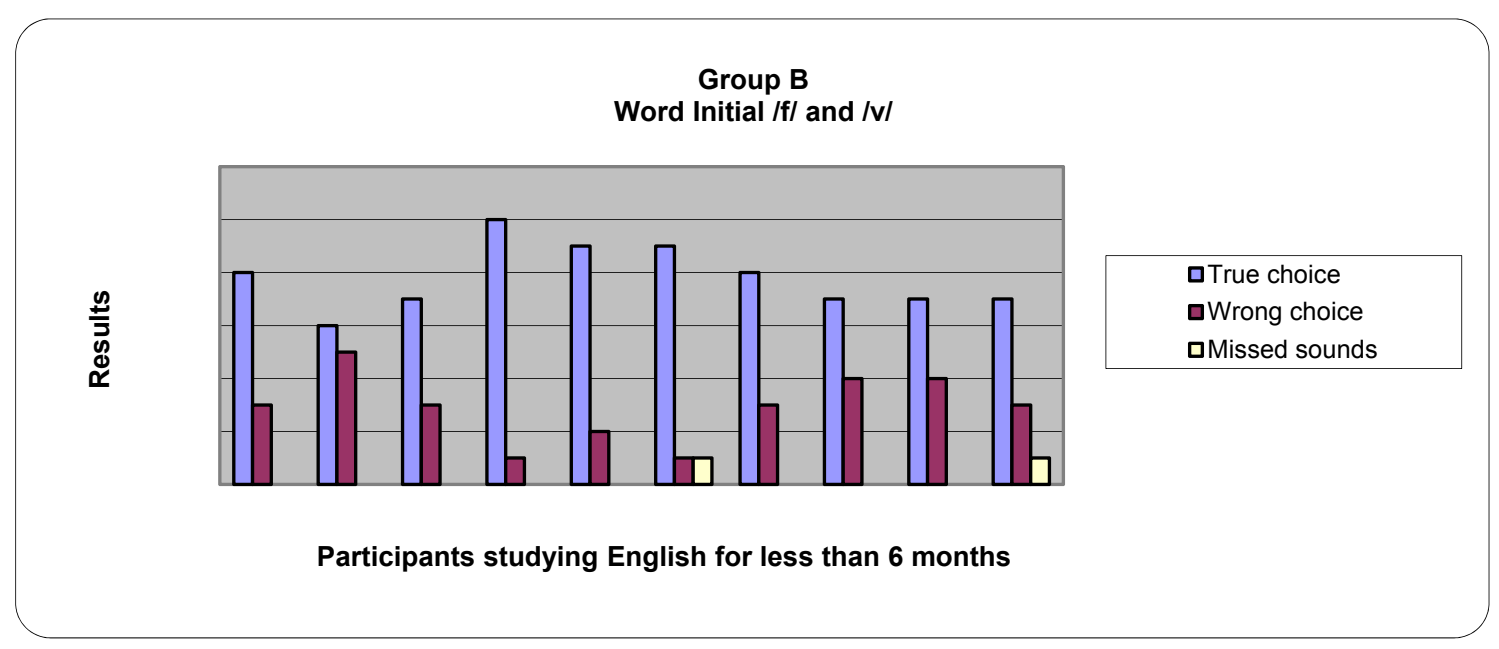

Figure 6. Participants studying English for less than six months in an English-speaking country

Group C, on the other hand, had a better environment as they had been studying English in Australia for many years. So, they had an advantage similar to Group A. As well, they were exposed to English at younger ages. However, five sounds were chosen wrongly. Also, three different participants chose three missed sounds where they could not recognize the correct sound, as seen in the following figure.

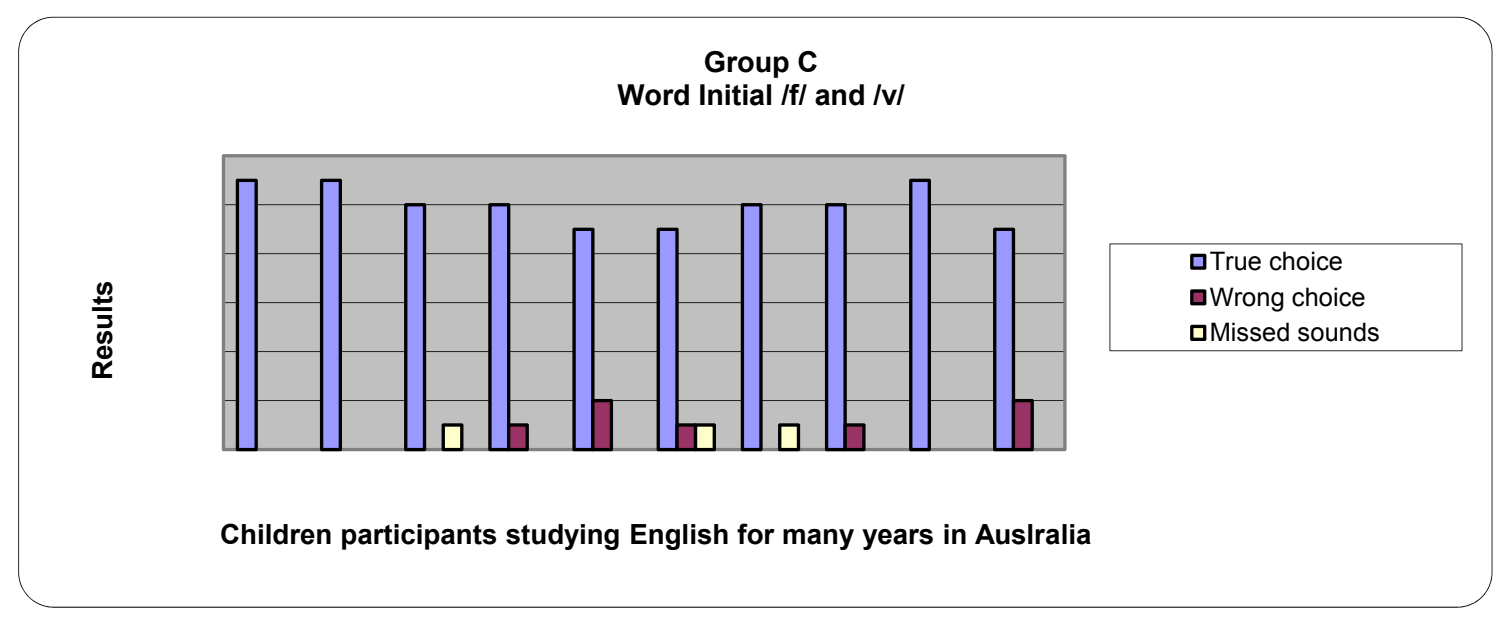

Figure 7. Children studying English for many years in an English-speaking country

Group D shows to have contained ten high misperceptions of the initial sounds $/ \mathrm{f} /$ and $/ \mathrm{v} /$ with a variation in scores from the lowest three wrong choices to eight wrong choices. Also, eight participants had difficulties in choosing the correct sounds, with a range from zero for two participants and to four missed sounds for one participant. As stated before, this proves that exposure to English in real situations and/or environments have a positive impact on the perceptions of the initial sounds /f/ and /v/. Consider the following figure: 


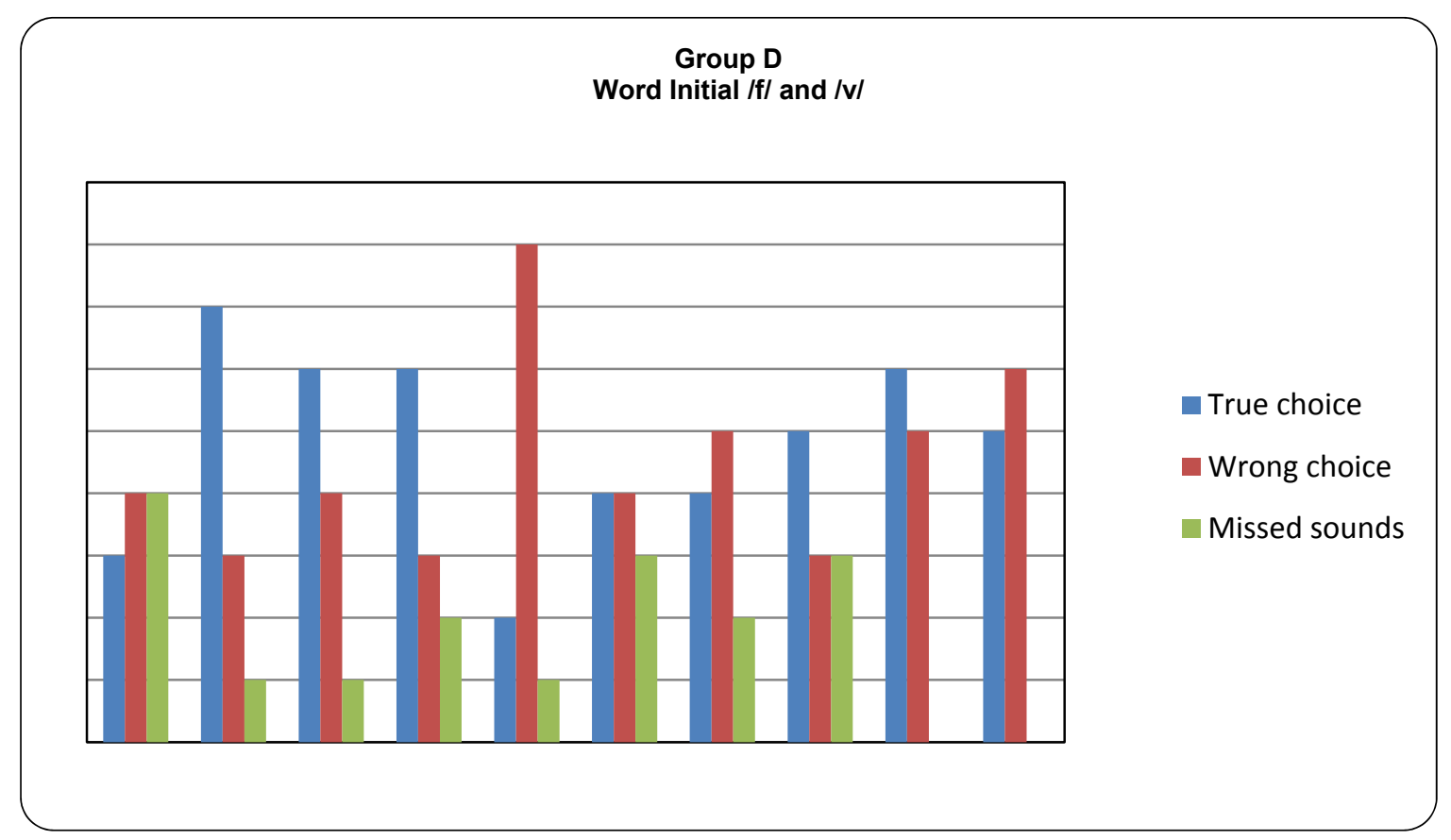

Figure 8. Participants studying English for many years in Saudi Arabia

\subsubsection{The Medial /p/ and /b/ Sounds}

The medial bilabial sounds $/ \mathrm{p} /$ and $/ \mathrm{b} /$ show the highest degree of misperceptions with some variations from one group to another. One main reason behind this is that all the recorded words are not real words (non-sense words). Thus, by having this result and by having misperception in other environment, it can be sound proof that some correctly chosen phonemes were a result of being real recognizable words other than being a true perception according to the group and their level of English and/or their previous exposure to English.

Unlike the initial sound $/ \mathrm{p} /$ and $/ \mathrm{b} /$, the medial position showed a higher degree of misperception for participants who had been studying English for many years in Australia. Only one participant was able to get all sounds correct. The other nine participants made many wrong choices starting from one to four while three participants had some missed sounds. This means they had problems in deciding the correct choice ranging from one missed sound to five missed sounds, as shown in the figure below.

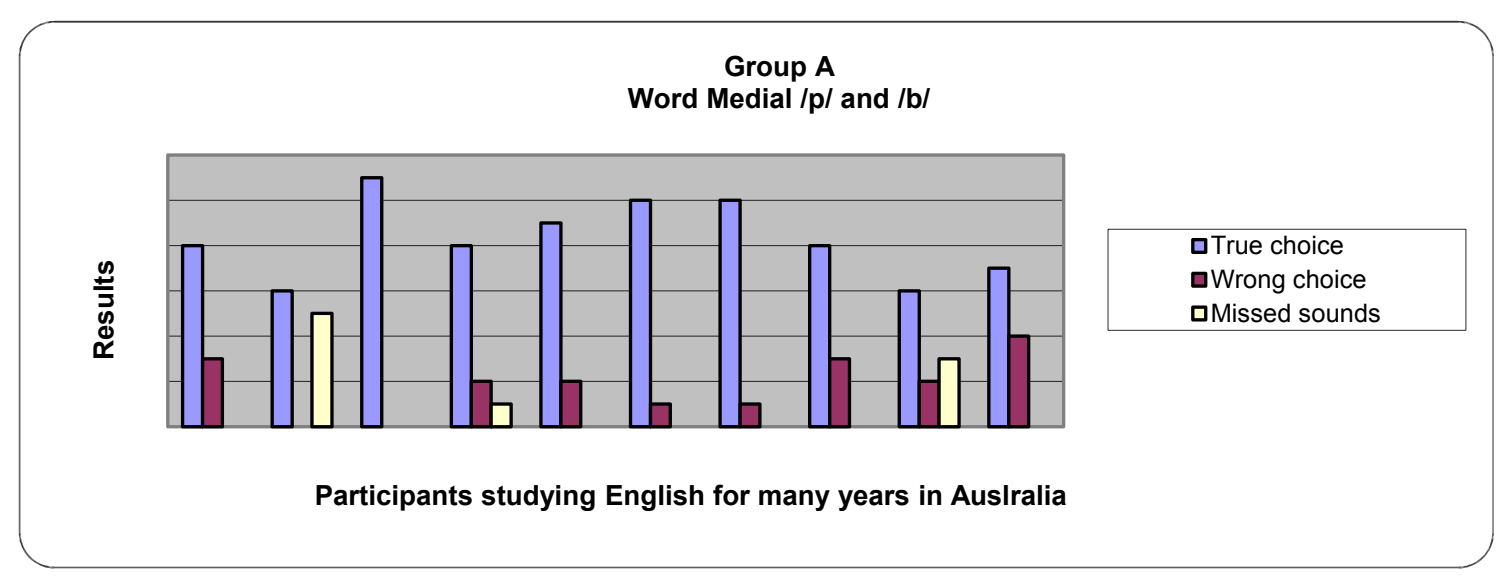

Figure 9. Participants studying English for many years in an English-speaking country

Participants, who had been studying English for less than six months in Australia, also showed a higher degree of misperceptions of the medial $/ \mathrm{p} /$ and $/ \mathrm{b} /$. Responses ranged from two to seven wrong choices. Only two 
participants showed they were not able to decide two sounds in one case and one sound for the second case. Consider the following figure:

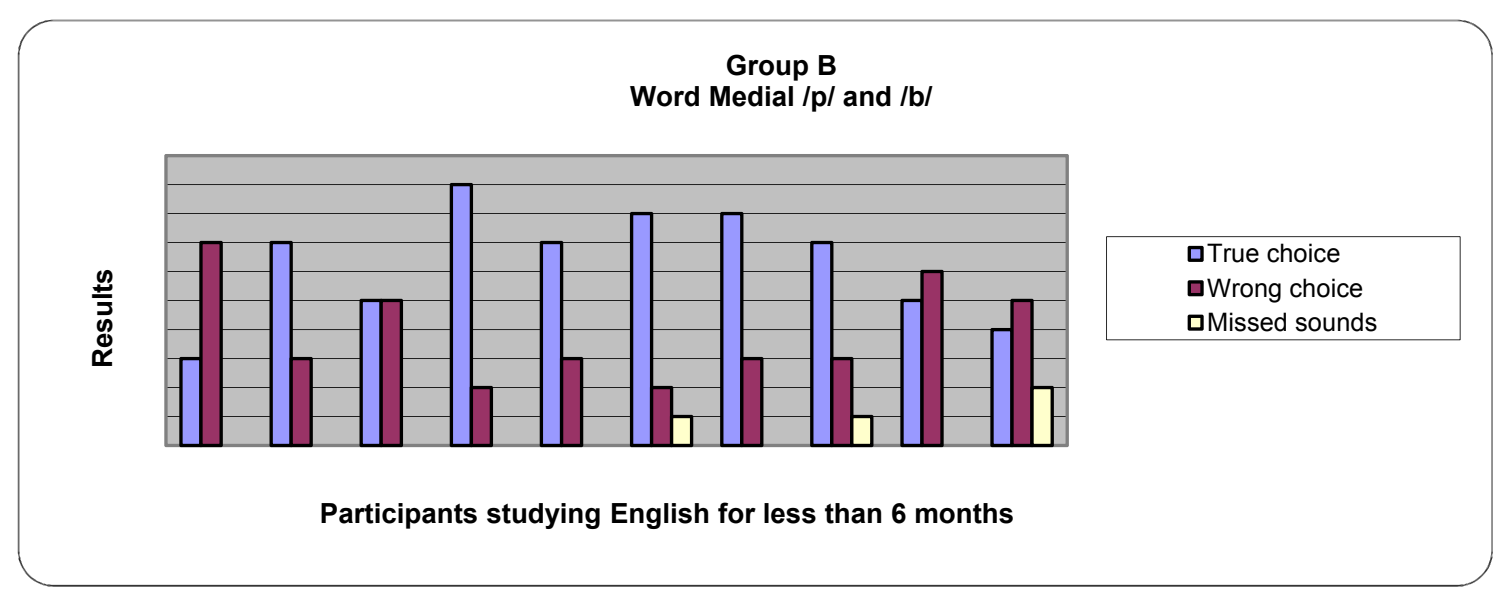

Figure 10. Participants studying English for less than six months in an English-speaking country

Interestingly, those children, who were studying English in Australia, have shown to have some misperceptions of $/ \mathrm{p} /$ and $/ \mathrm{b} /$ in the medial position. Only two participants scored all the ten sounds correctly. The wrong choices range from one to three. Only one participant was shown to have one missed sound, as indicated the figure below. I suggest that this proves that non-native speakers of English have problems with the perception of $/ \mathrm{p} / \mathrm{and} / \mathrm{b} /$ regardless of their English proficiency.

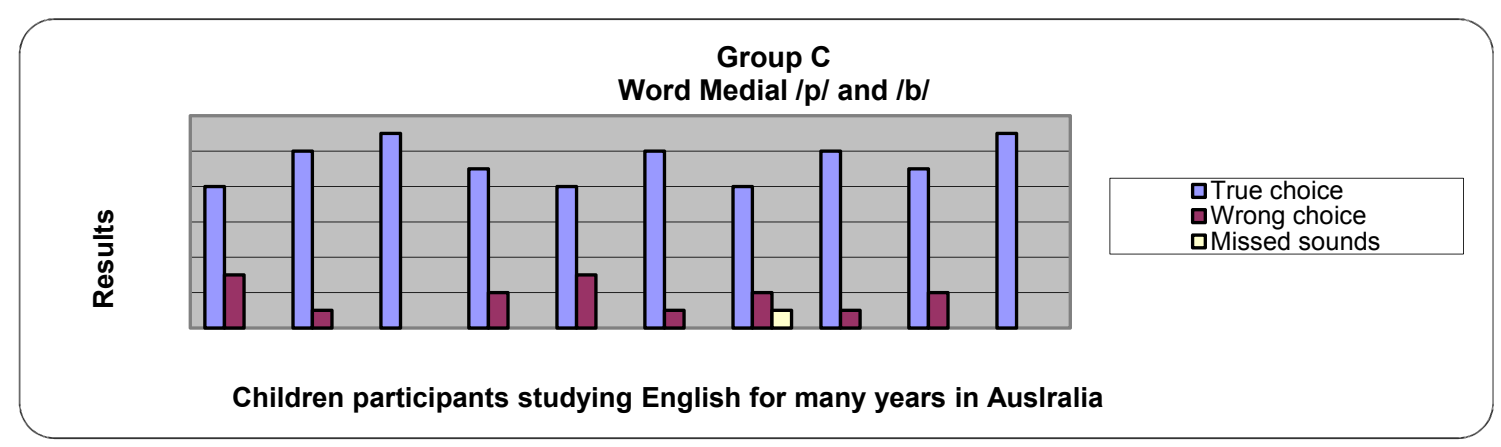

Figure 11. Children studying English for many years in an English-speaking country

Participants, who had studied English for many years in Saudi Arabia, scored the lowest score for the true choices of the medial $/ \mathrm{p} /$ and $/ \mathrm{b} /$. Their wrong choices are between three to seven out of ten different sounds. By saying that, it means that this is the highest misperception of the bilabial sound in the medial position with comparison to all the other three groups. Consider the following: 


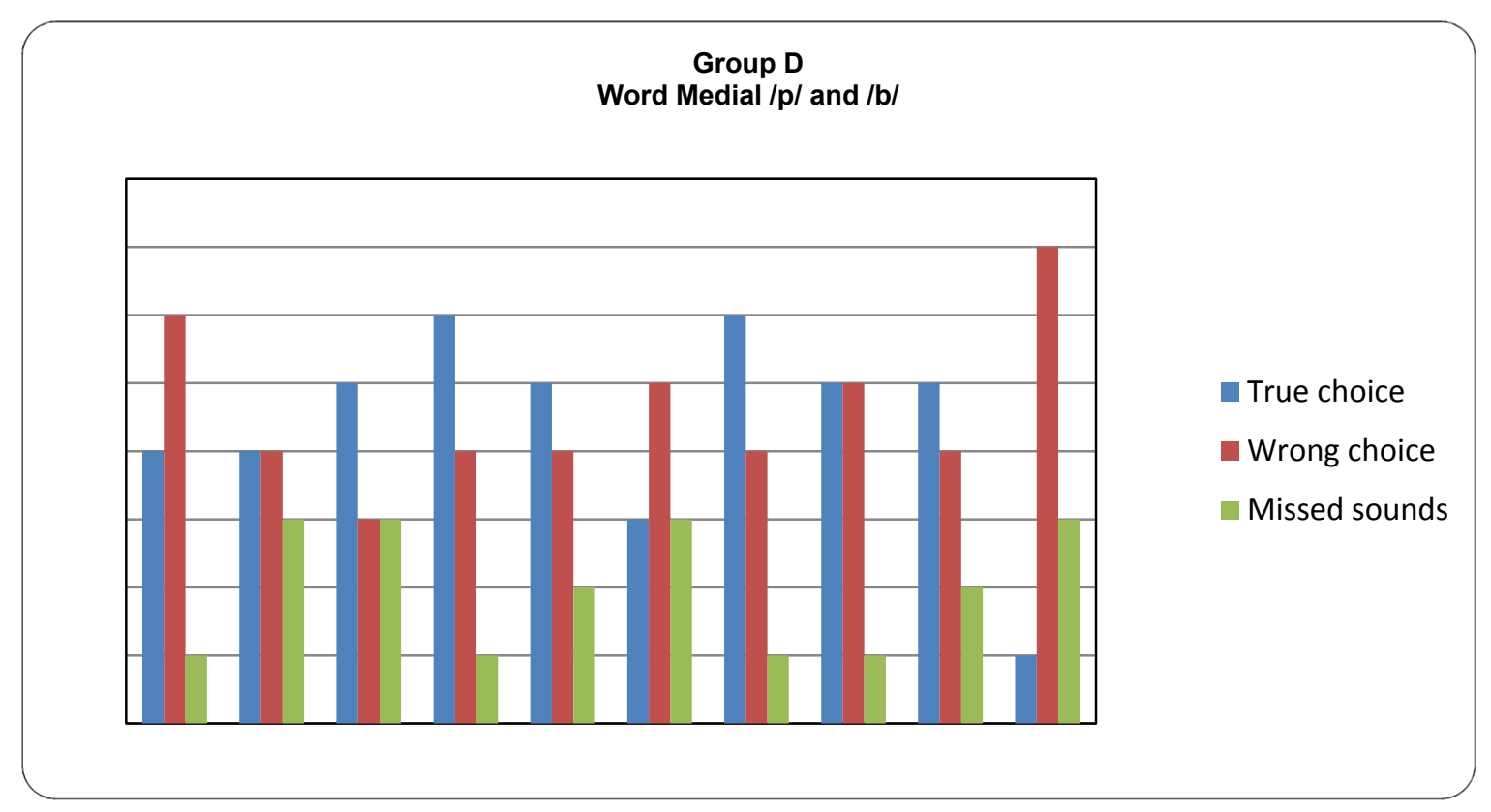

Figure 12. Participants studying English for many years in Saudi Arabia

\subsubsection{The Medial /f/ and /v/ Sounds}

On the other hand, the medial labio-dental sounds $/ \mathrm{f} /$ and $/ \mathrm{v} /$ indicate that the participants who lived and studied in Australia for many years have higher scores of true choices as was expected connecting this result to their long period of immersion in an English-speaking environment along with a greater exposure to English. However, six of the participants also made some wrong choices including three missed sounds. I suggest that the wrong choices happened as a result of the close environment for those participants. Some participants live in English-speaking countries; nevertheless, they practice their mother tongue language most of the time with their families and/or their friends. Consider the following figure:

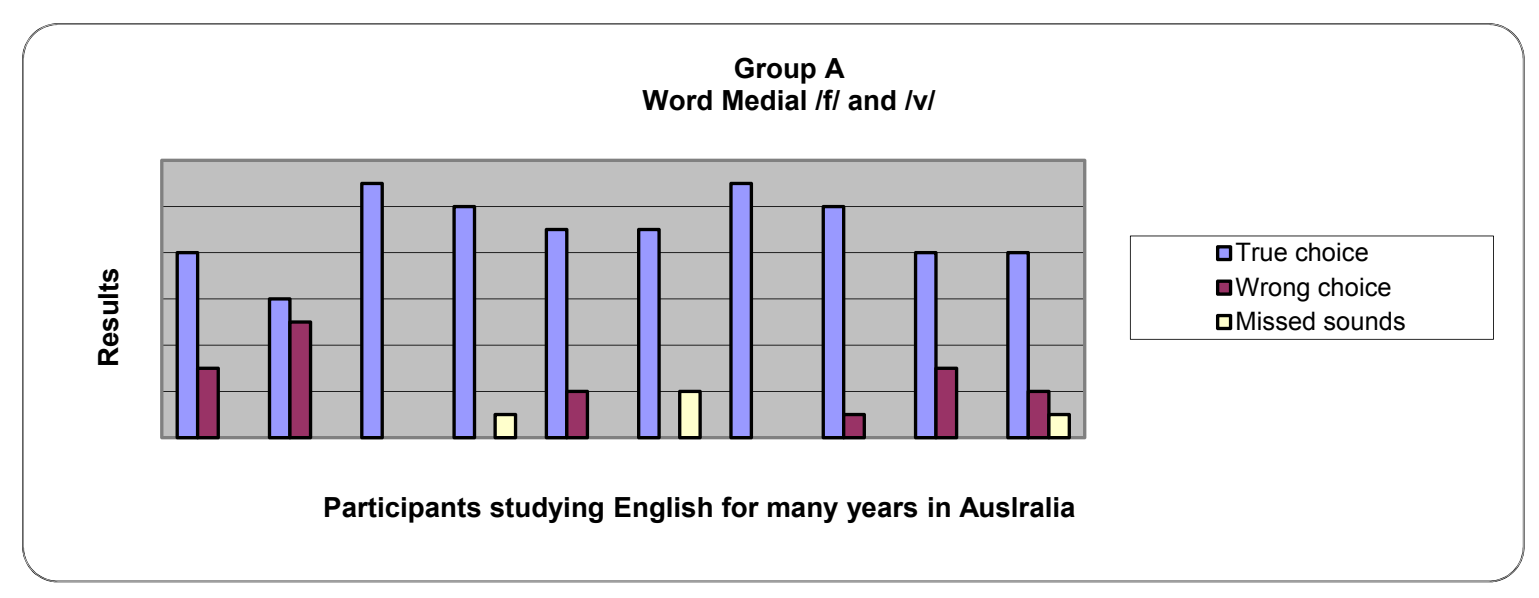

Figure 13. Participants studying English for many years in an English-speaking country

The experiment revealed that participants, who had had similar environment and exposure to English as Group A but for a shorter period of time, experienced some problems perceiving the labio-dental sounds $/ \mathrm{f} / \mathrm{and} / \mathrm{v} / \mathrm{in}$ the medial position. All subjects were shown to have wrong choices ranging from two to five wrong choices. Four participants have missed some sounds, too. 


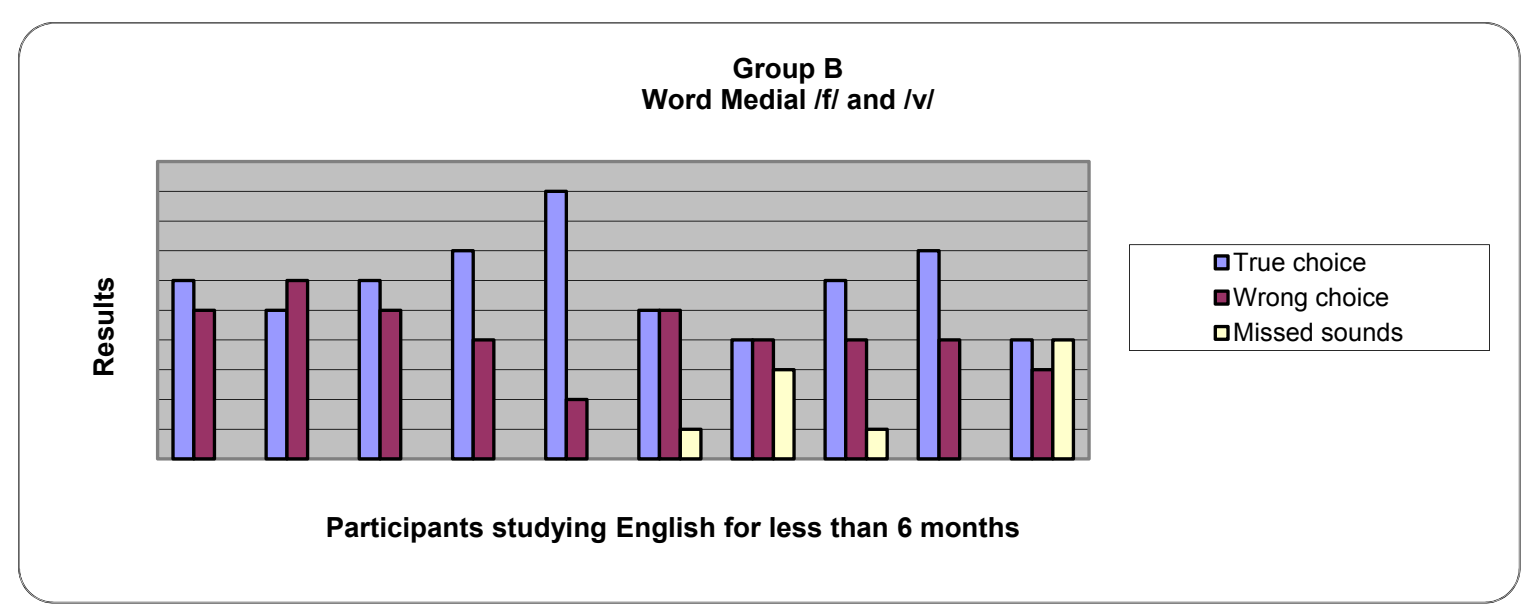

Figure 14. Participants studying English for less than six months in an English-speaking country

Group C, representing children studying English in Australia, eight participants made wrong choices. Only one participant missed a sound. This happened as all the recorded words are non-sense words (unreal words) as shown in the following figure.

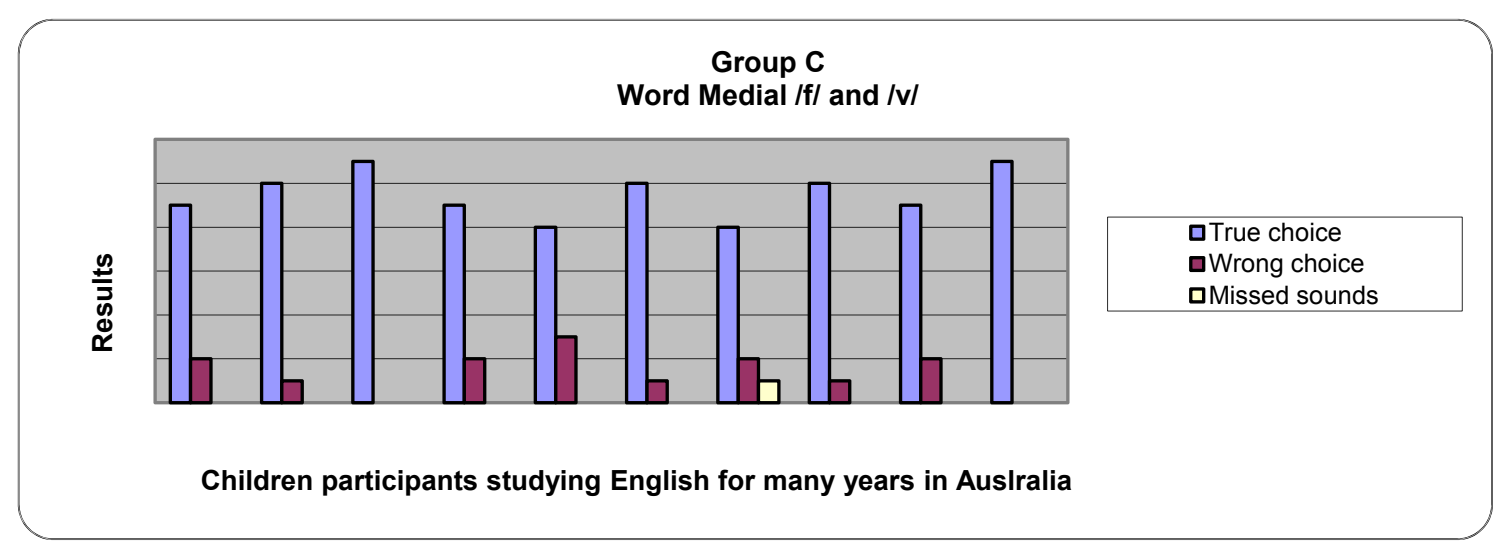

Figure 15. Children studying English for many years in an English-speaking country

Group D made many wrong choices and many missed sounds, with some variations between the participants. Those participants studied English in Saudi Arabia. All participants made wrong choices ranging from three to eight wrong choices. Also, all participants have missed sounds and ranged from one missed sound to four missed sounds, as seen in the following figure. 


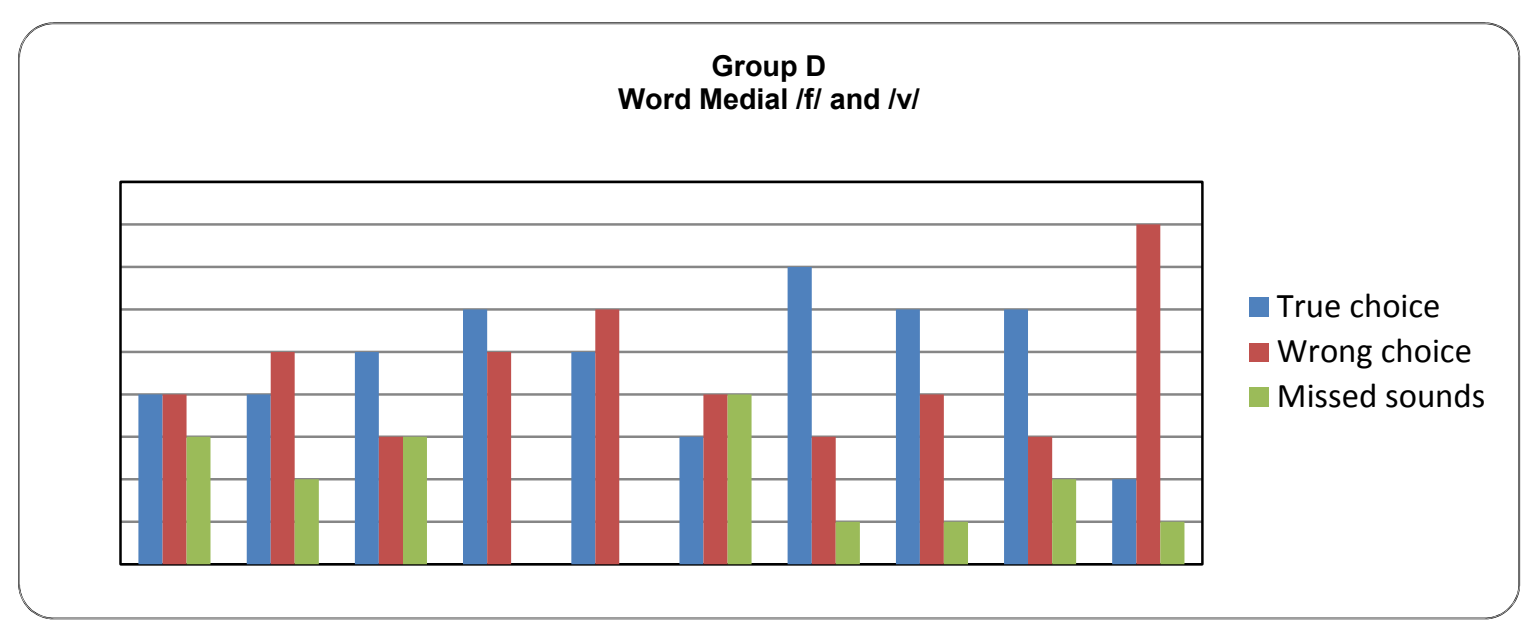

Figure 16. Participants studying English for many years in Saudi Arabia

\subsubsection{The Final /p/ and /b/ Sounds}

Regarding the final bilabial sounds $/ \mathrm{p} /$ and $/ \mathrm{b} /$, the experiment shows that the degree of the misperception increased in all cases including children. With regard to Group A which was expected to score good results in this experiment as they had been located in Australia for many years, six participants out of the ten scored misperceptions. One participant made five wrong choices which resulted in this participant missed $50 \%$, when this is linked back to the environment where they practice English on a daily base. Three other participants demonstrated having issues with some sounds where they were not able to decide the sound they heard. Consider the following figure:

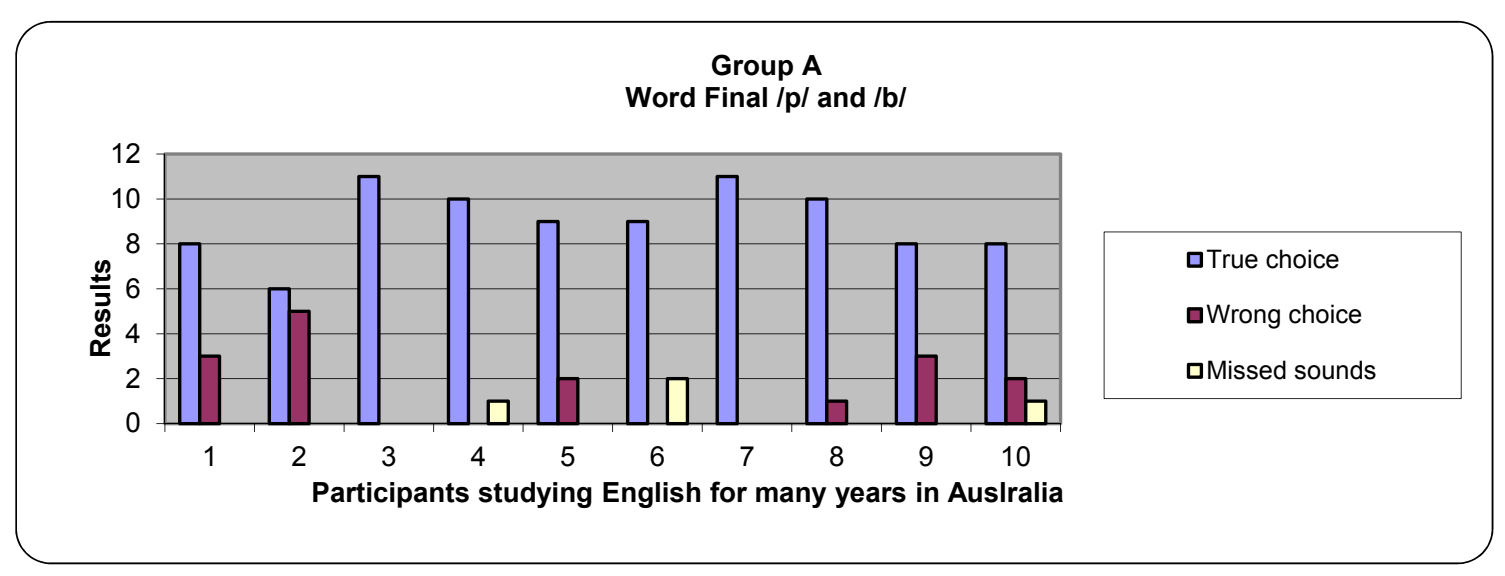

Figure 17. Participants studying English for many years in an English-speaking country

On the other hand, those subjects, who are in Group B, experienced more misperceived sounds, which ranged from two wrong choices to four choices. Only one participant missed a sound, as shown in the figure below. 


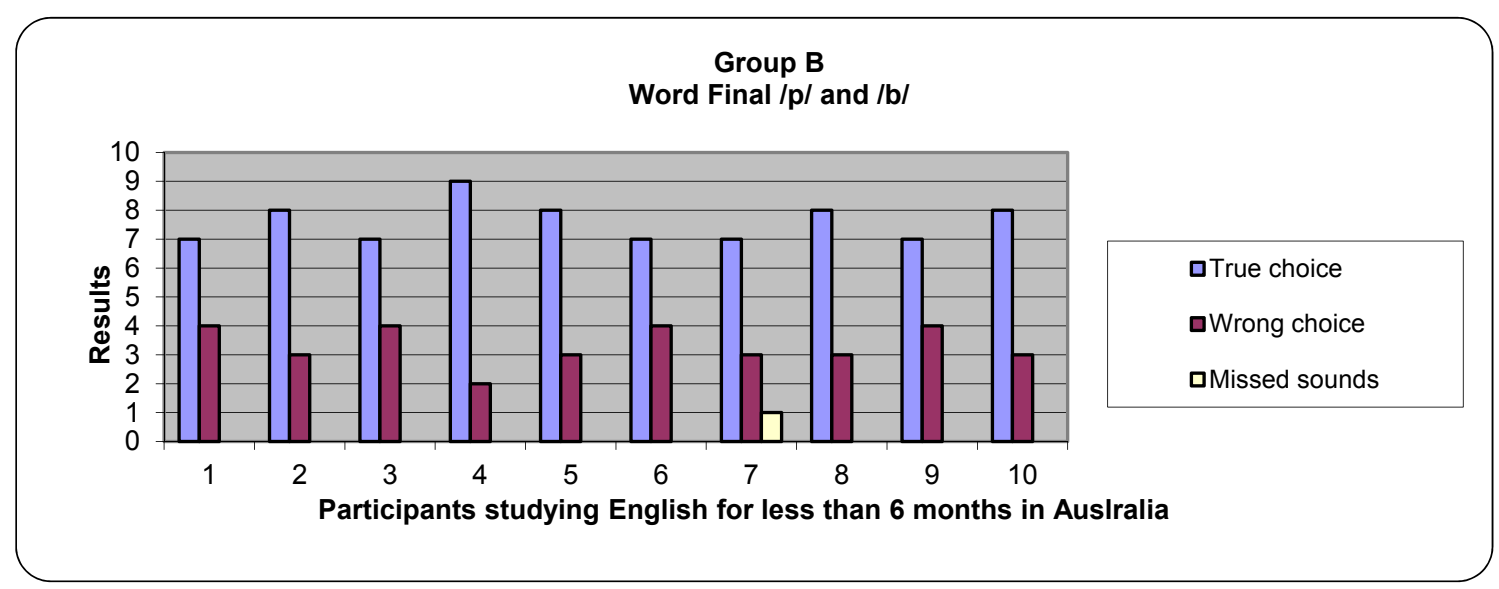

Figure 18. Participants studying English for less than six months in an English-speaking country

Surprisingly, Group C, whose participants had experienced a better learning environment and had met all the positive criteria to learn a language as a second language, showed misperceptions for seven of the participants. Only two children made no wrong choices. Two participants had some missed sounds. However, this group had the least misperceptions with comparison to all the other three groups. Consider the figure below.

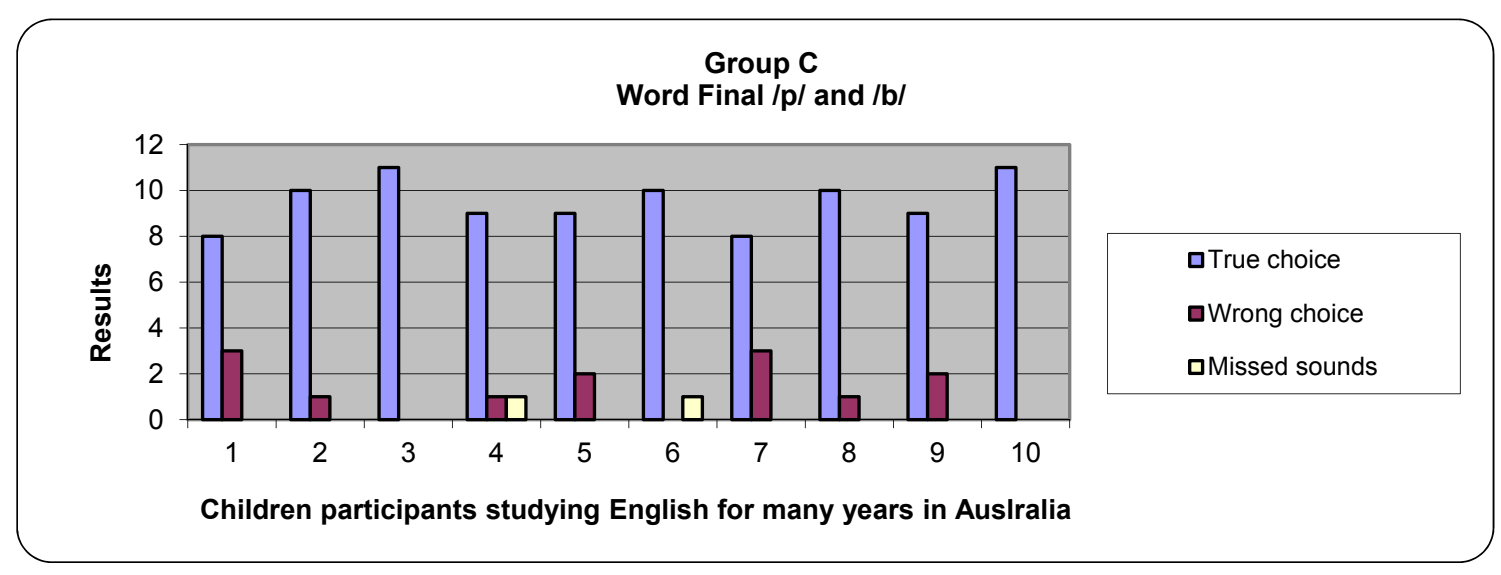

Figure 19. Children studying English for many years in an English-speaking country

Group D had the highest misperceptions including both the wrong choices and the missed sounds. Wrong choices ranged from three to eight. Missed sounds also ranged from one missed sound to four. Generally, this result was expected due to the exposure and the environment factors. Consider the following: 


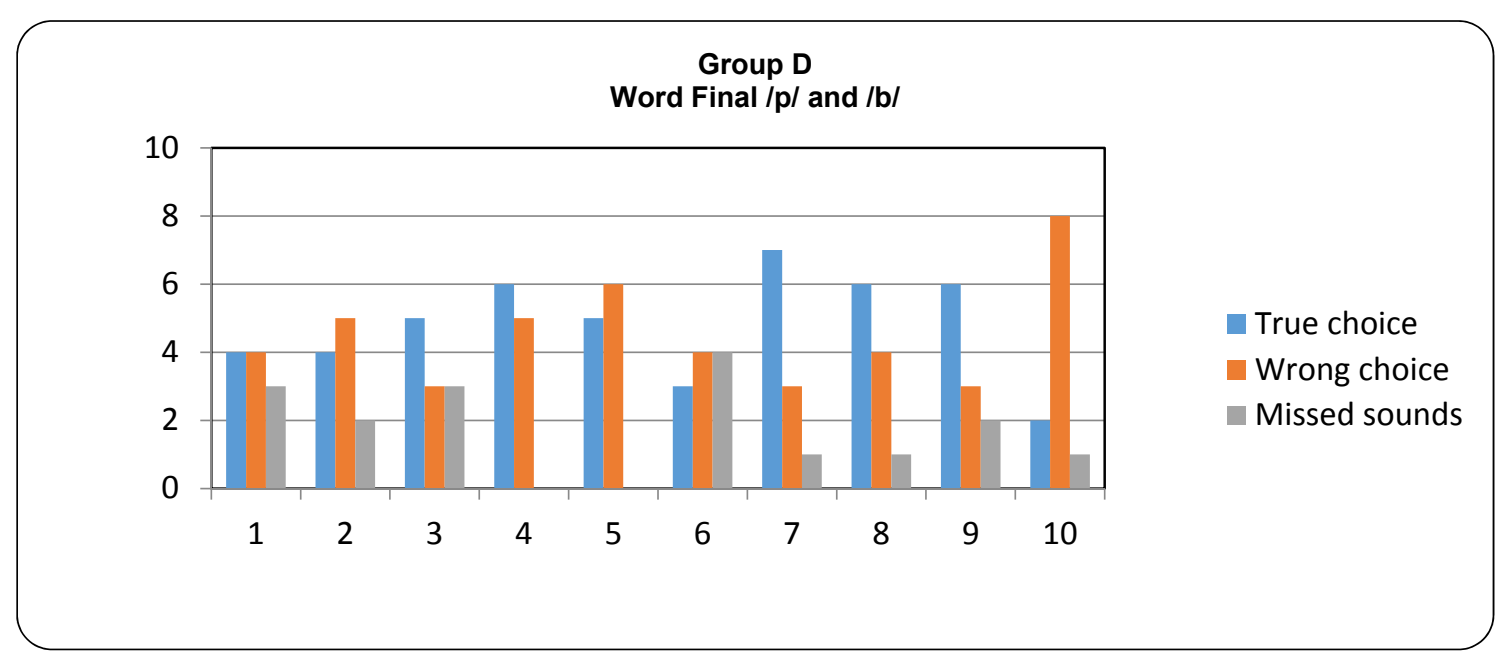

Figure 20. Participants studying English for many years in Saudi Arabia

\subsubsection{The Final/f/ and /v/ Sounds}

On the other side of the scale, labio-dental sounds /f/ and /v/, in the final position, show a higher misperception average from the bilabial sounds discussed above. Like the previous positions, participants, in group A, were shown to have very few wrong choices and/or missed sounds. Only one participant was able to choose all sounds correctly, as shown below.

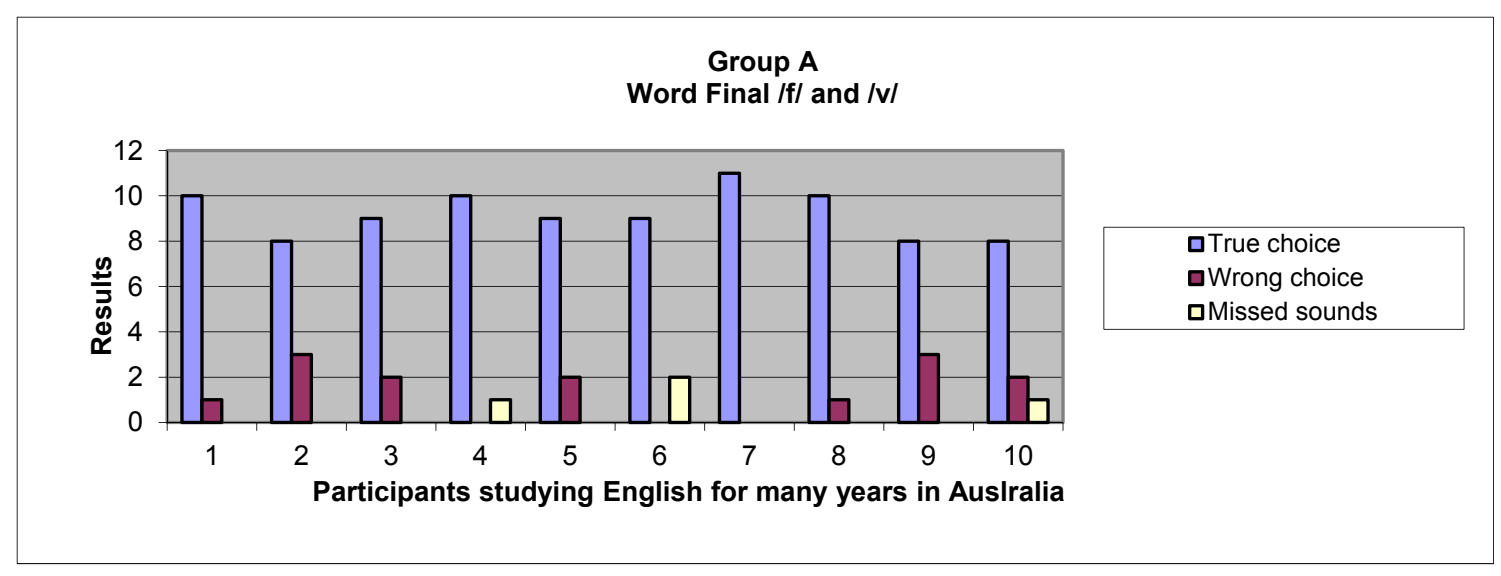

Figure 21. Participants studying English for many years in an English-speaking country

Group B also scored higher misperceptions with regard to those in Group A as they had spent less than six months in Australia. The highest score for true choices was nine whereas the highest number of wrong choices was five. Only four participants experienced difficulties deciding what the sound they heard. Consider the following figure. 


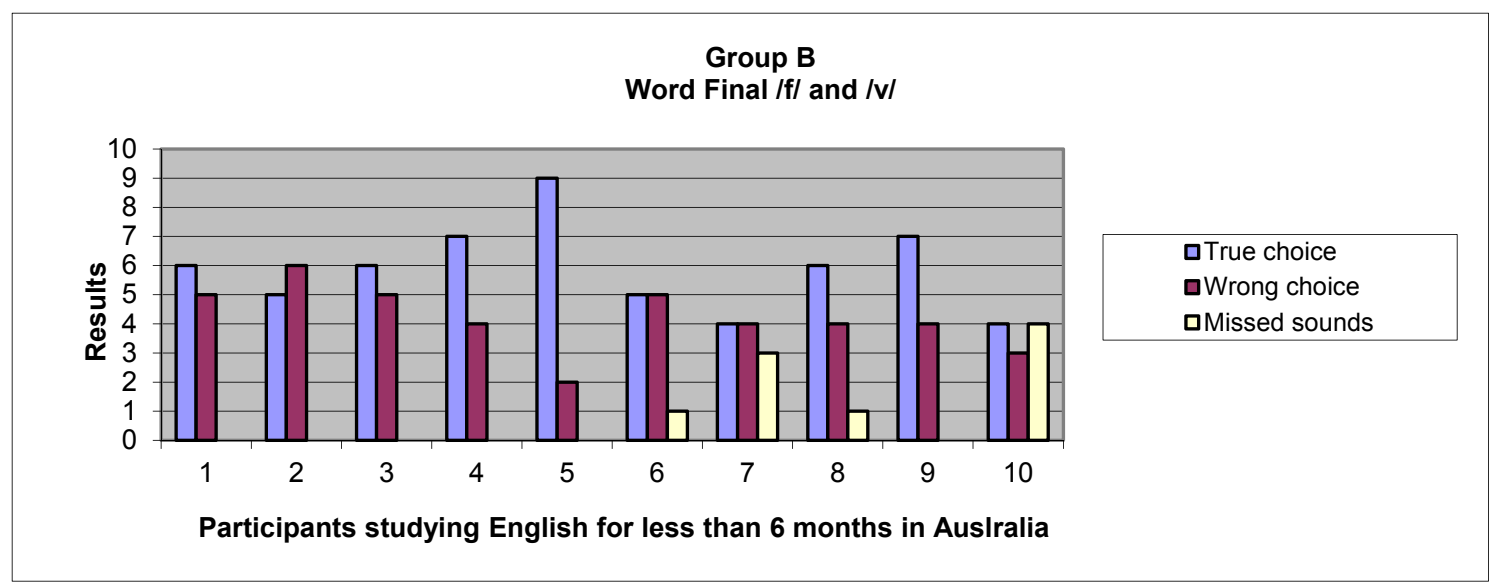

Figure 22. Participants studying English for less than six months in an English-speaking country

Group C showed the highest score with regard to the final labio-dental sounds /f/ and /v/. Although they scored the lowest misperceptions among all the groups, they also made some wrong choices as well as missed sounds. The true choices ranged from nine true choices (the lowest) and raised up to eleven true choices (the highest), as seen in the following figure.

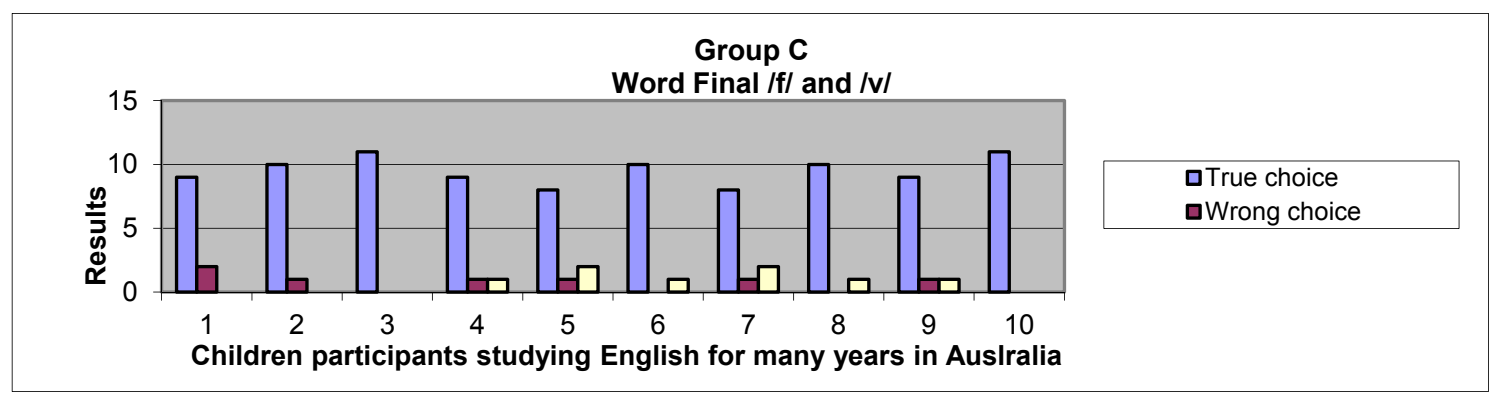

Figure 23. Children studying English for many years in an English-speaking country

On the other hand, Group D had the lowest score among all the other three groups, ranging from three to eight wrong choices. In addition, they also had some missed sounds ranging from one to four in their responses. Consider the following:

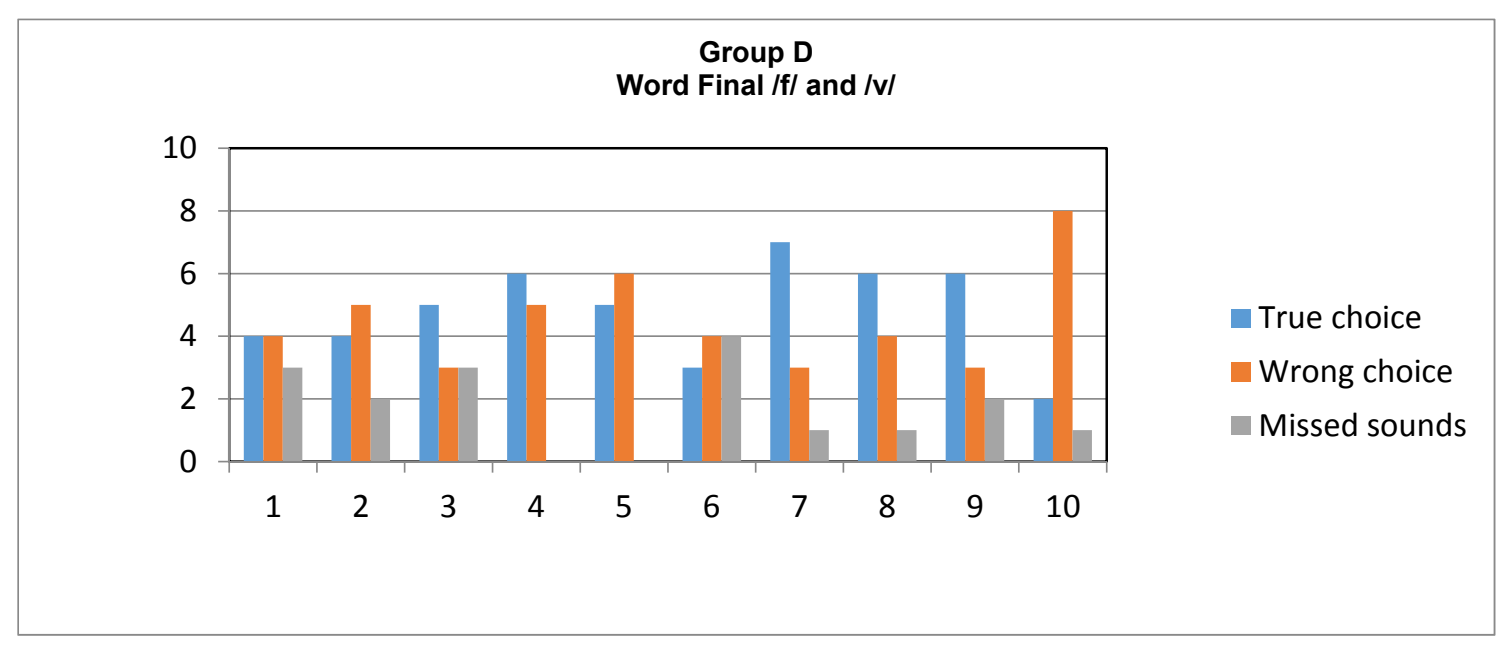

Figure 24. Participants studying English for many years in Saudi Arabia 


\section{Conclusion}

This paper explores the perception of four different phonemes in English: the bilabial stops (/p/and $/ \mathrm{b} /)$ and the labio-dental fricatives (/f/ and /v/) in Saudi learners of English. It was claimed that Saudi second language learners of English misperceive sounds such as $/ \mathrm{p} /$ and $/ \mathrm{v} /$ when learning English especially for those learners who have had less exposure to English or those who do not have a conductive environment for learning. Voicing cannot be the reason behind this misperception as has been proven due to the misperception of sounds regardless of being voiced or not. Some sounds such as the Medial Bilabial sounds $/ \mathrm{p} /$ and $/ \mathrm{b} /$ indicate more misperception than others. However, according to the data, it is clear that there is a misperception but it is not definite due to the conditions in which this project took place where participants did not have the chance to do the experiment in a phonetics laboratory. There might be other factors related to some technical issues, as well. However, this study sheds some lights on other factors that might contribute to the misperception such as age, education, environment and exposure to English.

Therefore, as noted previously, it is important to state that this misperception occurs more evidently with subjects who are learning English as learners in a non-native speaking English country or as beginners (learning English for less than six months). It happens more rarely with young learners, who are learning English in an English-speaking country. Participants, who are studying English in Australia for more than three years, have the same problem but with less degree. Therefore, it is believed that there should be a significant relation between the misperceptions and what is happening in the learner's brain processing. It is also claimed that the early start of learning language can have its impact on the perception process. Therefore, it is also important to bear in mind that there is another window to look at this issue, which is through the learners' brain processing with production and perception training experiments. Finally, I believe that this paper strongly suggests that teaching the correct articulation of English phonemes for Saudi learners of English as a second language in school is essential.

\section{References}

Al-Khairy, M. (2005). Acoustic Characteristics of Arabic Fricatives. University of Florida, Ph.D. dissertation. USA.

Alkhuli, M. (2007). Comparative Linguistics: English and Arabic. Dar Alfalah Publisher, Jordan.

Alshangiti, W. (2015). Speech production in adult Arabic learners of English: A comparative study of the role of production and perception training in the acquisition of British English vowels. Ph.D. thesis, University College London, UK.

Beardsmore, H. (1986). Bilingualism: Basic principles. Clevedon, England: Multilingual Matters.

Buali, I. (2010). The perception and production of /p/ in Saudi Gulf Arabic English: A variation perspective. MA thesis, University of Concordia, Canada.

Cheon, S. Y. (2005). Production and perception of phonological contrasts in second language acquisition: Korean and English fricatives. Ph.D. thesis, University of Hawaii, USA.

Chomsky, N. (1965). Aspect of the Theory of Syntax. MIT Press. https://doi.org/10.21236/AD0616323

Elkhair, M. I. H. (2014). Pronunciation Problems: A Case Study of English Students at Sudan University of Science and Technology. English Language and Literature Studies, 4(4), 31-44. https://doi.org/10.5539/ells.v4n4p31

Flege, J. E. (1980). Phonetic approximation in second language acquisition. Language Learning, 30(1), 117-134. https://doi.org/10.1111/j.1467-1770.1980.tb00154.x

Flege, J. E., \& Port, R. (1981). Cross-language phonetic interference: Arabic to English. Language and Speech, 24(2), 125-146. https://doi.org/10.1177/002383098102400202

Fromkin, V., Rodman, R., Hyams, N., Collins, P., \& Amberber, M. (2018). An Introduction to Language (9th ed.). Nelson Thomson Learning Pty Limited. Australia.

Giegerich, H. J. (1992). English phonology: An introduction. Cambridge: Cambridge University Press. https://doi.org/10.1017/CBO9781139166126

Hattori, K., \& Iverson, P. (2009). English /r/-/1/ category assimilation by Japanese adults: Individual differences and the link to identification accuracy. The Journal of the Acoustical Society of America, 125(1), 469-479. https://doi.org/10.1121/1.3021295

Jensen, J. T. (1993). English phonology. Amsterdam; Philadelphia: J. Benjamins Pub. Co. https://doi.org/10.1075/cilt.99 
Khattab, G. (2000). VOT Production in English and Arabic bilingual and monolingual children. Leeds Working Papers in Linguistics and Phonetics, 8, 95-122.

Kusumoto, Y. (2012). Between perception and production: Is the ability to hear L1-L2 sound difference related to the ability to pronounce the same sounds accurately? Polyglossia, 22, 15-33.

Leelawadee, M. (2011). The production of $/ r /$ and $/ / /$ by M.6 students in the English program at Suankularbwittayalai Rangsit School. Bangkok, Thailand: Language Institute, Thammasat University.

Lenneberg, E., Chomsky, N., \& Marx, O. (1967). Biological foundations of language (Vol. 68). New York: Wiley.

Mack, M. (1989). Consonant and vowel perception and production: Early English-French bilinguals and English monolinguals. Perception and Psychophysics, 46(2), 187-200. https://doi.org/10.3758/BF03204982

Maddieson, I. (1984). Patterns of Sounds. Cambridge University Press. https://doi.org/10.1017/CBO9780511753459

McMahon, A. M. S. (2002). An introduction to English phonology. Edinburgh: Edinburgh University Press.

Mohammad, H. K., \& Mahmud, K. A. (2017). An investigation into Online Pronunciation Problems of HAUSA-SPEAKING Learners of English. International Journal of Education and Teaching, 4(1), 61-64.

Moskowitz, B. (1975). The Acquisition of Fricatives: A Study in Phonetics and Phonology. Journal of Phonetics, 3, 141-150. https://doi.org/10.1016/S0095-4470(19)31361-0

Moustafa, M. H. (1979). Perception analysis. The Modern Language Journal, 63(8), 435-441. https://doi.org/10.1111/j.1540-4781.1979.tb02485.x

Nakshabandi, A. (1988). A Description Study of the Phonology and Morphology of the Abha Dialect. Washington, D.C.

Penfield, W. (1953). A consideration of the neurophysiological mechanisms of speech and some educational considerations. Proceedings of the American Academy of Arts \& Sciences, 82, 201-214. https://doi.org/10.2307/20023716

Penfield, W., \& Roberts, L. (1959). Speech and brain mechanisms. Princeton, NJ: Princeton University Press. https://doi.org/10.1515/9781400854677

Phosrithong, P. (2017). A study of the perception of English initial consonant sounds. MA thesis, Thammasat University. Thailand.

Pirello, K., Blumstein, S., \& Kurowski, K. (1997). The Characteristics of Voicing in Syllable-initial fricatives in American English. Journal of Acoustical Society of America, 101, 3754-3765. https://doi.org/10.1121/1.418334

Prince, A., \& Smolensky, P. (1993). Optimality Theory: Constraint interaction in generative grammar. Cambridge, MA: MIT Press.

Rasmussen, Z. (2007). The interlanguage speech intelligibility benefit: Arabic-accented English (thesis, University of Utah).

Roca, I., \& Johnson, W. (2004). A Course in Phonology (6th ed.). Oxford: Blackwell Publishing.

Sasiwimon, P. (2013). The study of Thai EFL learners' production of polysyllabic English word stress. Bangkok, Thailand: Language Institute, Thammasat University.

Selinger, H., Krashen, S., \& Ladefoged, P. (1975). Maturational constraints on the acquisition of second language accent. Language Sciences, 36, 20-22.

Waston, J. (2002). The Phonology and Morphology of Arabic (1st ed.). Oxford University Press. New York.

Wei, Y. F., \& Zhu, Y. L. (2002). Insight into English Pronunciation Problems of Thai Student. Paper presented at the Annual Meeting of the Quadruple Heix (8th, Aril 6, 2002)

Yule, G. (2020). The Study of language (7th ed.). Cambridge: Cambridge University Press.

Zhang, F., \& Yin, P. (2009). A study of pronunciation problems of English learners in China. Asian Social Science, 5(6), 141-146. https://doi.org/10.5539/ass.v5n6p141 


\section{Copyrights}

Copyright for this article is retained by the author, with first publication rights granted to the journal.

This is an open-access article distributed under the terms and conditions of the Creative Commons Attribution license (http://creativecommons.org/licenses/by/4.0/). 